Board of Governors of the Federal Reserve System

International Finance Discussion Papers

Number 616

June 1998

\title{
EXOGENEITY, COINTEGRATION, AND ECONOMIC POLICY ANALYSIS
}

Neil R. Ericsson, David F. Hendry, and Grayham E. Mizon

NOTE: International Finance Discussion Papers are preliminary materials circulated to stimulate discussion and critical comment. References to International Finance Discussion Papers (other than an acknowledgment that the writer has had access to unpublished material) should be cleared with the author or authors. Recent IFDPs are available on the Web at www.bog.frb.fed.us. 


\title{
EXOGENEITY, COINTEGRATION, AND ECONOMIC POLICY ANALYSIS
}

\author{
Neil R. Ericsson, David F. Hendry, and Grayham E. Mizon*
}

Abstract: This overview examines conditions for reliable economic policy analysis based on econometric models, focusing on the econometric concepts of exogeneity, cointegration, causality, and invariance. Weak, strong, and super exogeneity are discussed in general; and these concepts are then applied to the use of econometric models in policy analysis when the variables are cointegrated. Implications follow for model constancy, the Lucas critique, equation inversion, and impulse response analysis. A small money-demand model for the United Kingdom illustrates the main analytical points. This paper then summarizes the other articles in this issue's special section on Exogeneity, Cointegration, and Economic Policy Analysis.

Keywords: causality, equation inversion, impulse response analysis, invariance, Lucas critique, money demand.

JEL classifications: C50, E41.

\footnotetext{
${ }^{*}$ Forthcoming as the introduction to a special section on "Exogeneity, Cointegration, and Economic Policy Analysis" in the Journal of Business and Economic Statistics, 1998. The appendix to this discussion paper lists the articles appearing in that special section. The first author is a staff economist in the Division of International Finance, Federal Reserve Board, Washington, DC 20551 USA. The second author is Leverhulme Personal Research Professor of Economics at Nuffield College, Oxford OX1 1NF England. The third author is a Professor of Economics at the European University Institute, Florence I-50016 Italy, on leave from Southampton University. The authors may be reached on the Internet at ericsson@frb.gov, david.hendry@nuffield.oxford.ac.uk, and mizon@datacomm.iue.it respectively. The views in this paper are solely the responsibility of the authors and should not be interpreted as reflecting the views of the Board of Governors of the Federal Reserve System or of any other person associated with the Federal Reserve System. This paper is a revised version of Hendry and Mizon (1992). All numerical results were obtained using PcGive Professional Version 9.1; see Doornik and Hendry (1996). Financial support from the UK Economic and Social Research Council under grants R000233447 and L116251015 and from the EUI Research Council is gratefully acknowledged. We are indebted to Mike Clements, Jurgen Doornik, Massimiliano Marcellino, Jaime Marquez, Anders Rahbek, Mark Salmon, George Tauchen, Pravin Trivedi, Ken Wallis, Mark Watson, and two anonymous referees for helpful comments. This paper is being simultaneously circulated as a Working Paper by the Department of Economics at the European University Institute, and as International Finance Discussion Paper No. 616 by the Board of Governors of the Federal Reserve System. The latter can be obtained at www.bog.frb.fed.us/pubs/ifdp/1998/616/default.htm on the WorldWide Web.
} 
The assessment of alternative economic policies is one of the most challenging uses of econometric models. This paper discusses how the concepts of exogeneity and cointegration influence and help interpret the uses of econometric models in economic policy analysis. The main contribution of the paper is expositional - it unifies, supplements, and synthesizes previously disparate results on exogeneity, particularly those for cointegrated systems. Discussion focuses on econometric conditions for reliable conditional policy analysis: specifically, analysis based on an econometric model that characterizes the distribution of policy targets conditional on policy instruments. Relatedly, we consider limitations of some commonly used policy tools, including equation inversion and impulse response analysis. The econometric concepts of exogeneity, cointegration, causality, and invariance are vital in determining the usefulness of estimated models for economic policy. Throughout, this paper lays out the concepts and the structure of the modeling approach adopted in the other empirical papers of this special section of the Journal of Business and Economic Statistics.

Building on the work of Engle, Hendry, and Richard (1983), Section 1 reviews several econometric concepts, including the data generation process (as distinct from the econometric model), weak exogeneity and parameters of interest, strong exogeneity and Granger causality, super exogeneity and invariance, and parameter constancy. Section 2 discusses the cointegrated vector autoregression - a class of econometric models used throughout the rest of the paper - and uses it to illustrate long-run weak exogeneity and Granger causality. This section also considers some purposes of and conditions for conducting economic policy with econometric models. The next three sections focus on implications of the discussed econometric concepts for economic policy analysis. Particular issues include the Lucas critique (Section 3), inversion of econometric equations to determine policy effects (Section 4), and impulse response analysis (Section 5). Banerjee, Hendry, and Mizon (1996) and Hendry and Mizon (1998) discuss the additional, related policy issues of co-breaking, forecasting, policy credibility, expectations, and scenario studies. Section 6 illustrates the analytical discussion with a small econometric model using UK money-demand data. Finally, Section 7 summarizes the papers in this issue's special section and relates them to recent developments in cointegration and exogeneity in the context of economic policy analysis.

\section{Preliminaries and Notation}

Section 1.1 distinguishes between the data generation process and an econometric model thereof, as background for discussing exogeneity in Sections 1.2-1.4. Whether or not a variable is exogenous depends upon whether or not that variable can be 
taken as given without losing information for the purpose at hand. The distinct purposes of statistical inference (estimation and testing), forecasting, and policy analysis define the three concepts of weak, strong, and super exogeneity. Valid exogeneity assumptions permit simpler modeling strategies, reduce computational expense, and help isolate invariants of the economic mechanism, with the last being particularly important in policy analysis. Invalid exogeneity assumptions may lead to inefficient or inconsistent inferences and result in misleading forecasts and policy simulations. Weak, strong, and super exogeneity are defined relative to parameters of interest, whereas predeterminedness and strict exogeneity are not, making the latter two concepts of limited use for policy analysis; see Engle, Hendry, and Richard (1983) for details.

Sections 1.2, 1.3, and 1.4 discuss weak, strong, and super exogeneity respectively. Section 2 re-examines these notions when cointegration holds. Readers familiar with weak, strong, and super exogeneity may wish to skip directly to Section 2.

\subsection{The Data Generation Process and the Econometric Model}

The data generation process (DGP) is commonly defined in terms of the joint distribution of the data. Let the triple $(\Omega, \mathcal{F}, P(\cdot))$ denote a probability space, where $\Omega$ is the sample space for a vector of $N$ variables $x$ at time $t$ (denoted $x_{t}$ ) that characterize an economy, $\mathcal{F}$ is the event space of $\Omega$, and $P(\cdot)$ is the probability measure for the events in $\mathcal{F}$. Denote the history of the stochastic process $\left\{x_{t}\right\}$ up to time $(t-1)$ by $X_{t-1}$, which is $\left(X_{0}, x_{1}, \ldots, x_{t-1}\right)$ or $\left(X_{0}, X_{t-1}^{1}\right)$, where $X_{0}$ is the set of initial conditions and $X_{j}^{i}=\left(x_{i}, \ldots, x_{j}\right)$ for $i \leq j$. The DGP $D_{X}\left(X_{T}^{1} \mid X_{0}, \zeta\right)$ can be sequentially factorized as:

$$
D_{X}\left(X_{T}^{1} \mid X_{0}, \zeta\right)=\prod_{t=1}^{T} D_{x}\left(x_{t} \mid X_{t-1}, \zeta_{t}\right) \quad \zeta \in \mathbb{R}^{\ell},
$$

where $D_{X}\left(X_{T}^{1} \mid X_{0}, \zeta\right)$ is the joint density of $X_{T}^{1}$ given $X_{0}, \zeta$ is an $\ell \times 1$ vector of parameters, the sample is over $[1, T], \zeta_{t}$ is the subset of the parameters in $\zeta$ that enters the sequentially conditioned density $D_{x}\left(x_{t} \mid X_{t-1}, \zeta_{t}\right)$, and $\zeta=\left(\zeta_{1}, \ldots, \zeta_{T}\right)$ (ignoring redundancies). This formulation allows for nonconstant parameters, such

as transients due to regime shifts and structural breaks, so the sequential conditioning in (1) may include very complicated effects.

The econometric model for the full sample of $x_{t}$ may be factorized similarly:

$$
f_{X}\left(X_{T}^{1} \mid X_{0}, \theta\right)=\prod_{t=1}^{T} f_{x}\left(x_{t} \mid X_{t-1}, \theta\right) \quad \theta \in \Theta \subseteq \mathbb{R}^{n},
$$

where $f_{X}\left(X_{T}^{1} \mid X_{0}, \theta\right)$ represents the econometric model; $f_{x}\left(x_{t} \mid X_{t-1}, \theta\right)$ is the postulated, sequentially conditioned, joint density for $x_{t}$; and $\theta$ is an $n \times 1$ vector of 
parameters lying in the parameter space $\Theta$. Section 2 examines vector autoregressions as a particular form for the joint sequential density $f_{x}\left(x_{t} \mid \cdot\right)$. The econometric model is generally not the DGP, i.e., $f_{x}\left(x_{t} \mid \cdot\right) \neq D_{x}\left(x_{t} \mid \cdot\right)$. That lack of equality has implications for inferences about $\theta$. For example, if $\bar{\theta}_{T}[=\theta(\zeta)]$ is the full-sample pseudo-true value assuming constancy, $\bar{\theta}_{T}$ will minimize the Kullback-Leibler measure of distance between the two densities. A modeling strategy that aims to develop congruent and encompassing econometric models thus endeavors to keep such differences to a minimum; see Hendry (1995a), Mizon (1995), and Bontemps and Mizon (1997) inter alia.

Sometimes, joint modeling of all variables in $x_{t}$ is too difficult, so a subset of $m$ variables $y_{t}$ is modeled conditional on the remaining $k$ variables $z_{t}$, i.e., with $x_{t}$ partitioned as $x_{t}=\left(y_{t}^{\prime}: z_{t}^{\prime}\right)^{\prime}$ and $N=m+k$. Weak exogeneity of the conditioning variables $z_{t}$ is required for estimation of the conditional model for $y_{t}$ to be without loss of information relative to estimation of the joint model for $y_{t}$ and $z_{t}$.

Before turning to weak exogeneity itself, a few notational conventions are helpful to establish. The partitioning of $x_{t}$ into $y_{t}$ and $z_{t}$ implies similar partitionings of parameter vectors and matrices. Notationally, numerical subscripts 1 and 2 indicate the partitions associated with $y$ and $z$ respectively. The partition may be according to the density in which the parameter enters, as with $\lambda=\left(\lambda_{1}^{\prime}: \lambda_{2}^{\prime}\right)^{\prime}$, or corresponding to the variable multiplied. The context clarifies the precise usage. Pairs of numerical subscripts generally correspond to such partitions applied by row and by column. For example, the dynamic weighting matrix $\Gamma$ is $\left\{\Gamma_{i j}\right\}$, where $\{\cdot\}$ denotes the partitioned matrix consisting of (possibly matrix) elements $\Gamma_{i j}(i, j=1,2)$. For the cointegration weighting matrix $\alpha$ and the cointegrating vectors $\beta$, the column partition is by choice. A subscript $t$ on a parameter explicitly indicates potential time dependence.

\subsection{Parameters of Interest and Weak Exogeneity}

One useful approach to developing a model of $x$ may be to model some subset of $x$, conditional on the other variables in $x$. Weak exogeneity is the requirement for conditional estimation to be without loss of information from conditioning. Richard (1980) proposes the concept of weak exogeneity, building on Koopmans (1950); Engle, Hendry, and Richard (1983) analyze it in greater detail; and Ericsson (1992) provides an exposition. Florens and Mouchart (1985) and Boswijk (1994) discuss its relationship to the concept of $S$-ancillarity described by Barndorff-Nielsen (1978).

To state the conditions for weak exogeneity, it is necessary to transform the parameters of the joint distribution into those of the conditional and the marginal distributions. Hence, the original model parameters $\theta$ are transformed to the parameters $\lambda$ as $\lambda=g(\theta)$. The function $g(\cdot)$ defines a one-to-one mapping of $\theta$ into $\lambda$ for $\lambda \in \Lambda$, sustaining $\lambda^{\prime}=\left(\lambda_{1}^{\prime}: \lambda_{2}^{\prime}\right)$ and corresponding to the factorization of the joint density 
into a conditional density and a marginal density:

$$
f_{x}\left(y_{t}, z_{t} \mid X_{t-1}, \theta\right)=f_{y \mid z}\left(y_{t} \mid z_{t}, X_{t-1}, \lambda_{1}\right) \cdot f_{z}\left(z_{t} \mid X_{t-1}, \lambda_{2}\right)
$$

Such a factorization always can be achieved if $\lambda_{1}$ and $\lambda_{2}$ are defined to support it, although the resulting parameters may then be linked.

Whether or not conditional estimation will result in a loss of information depends crucially on what parameters are the focus of attention. Denote the $q(q \leq n)$ identified parameters of interest by the vector $\psi$. The factorization (3), in combination with the parameters of interest, permits defining weak exogeneity.

Definition 1 z $z_{t}$ is weakly exogenous for the parameters of interest $\psi$ if and only if:

(a) $\psi=\psi\left(\lambda_{1}\right)$, i.e., $\psi$ is a function of $\lambda_{1}$ alone; and

(b) $\lambda_{1}$ and $\lambda_{2}$ are variation free.

[See Engle, Hendry, and Richard (1983, Definition 2.5).]

Condition (a) ensures that $\psi$ can be learned from $\lambda_{1}$. Together, conditions (a) and (b) exclude the possibility that $\psi$ depends on $\lambda_{2}$, either directly [(a)] or indirectly $[(b)]$ : hence, no information about the parameters of interest can be derived from the marginal model. Because $\psi$ can be learned uniquely and completely from the conditional model, weak exogeneity is a sufficient condition for efficient inference on $\psi$ from the conditional model.

The marginal distribution of policy variables may be difficult to model empirically, due to changes in policy regime. In such a situation, valid conditioning on those variables can greatly assist empirical modeling. Although nonconstancy in the marginal process argues strongly for conditional modeling, it also places a premium on ensuring that weak exogeneity holds, both in sample and out of sample. Equally, the "exogenous" control of policy variables by a policy agency does not in itself justify conditioning on those variables, as Section 2.2 and Section 3 show.

Failure of either (a) or (b) precludes inference without loss of information when using the conditional model alone. The potential consequences of that information loss can be delineated into four distinct types. First, the parameters of interest cannot be obtained from the conditional model, as with errors-in-variables and simultaneity. Second, inference is distorted, even though $\psi$ is obtained, as for unit-root processes in which $\psi$ (the cointegrating vector, say) depends on both $\lambda_{1}$ and $\lambda_{2}$; see Phillips and Loretan (1991) and Hendry (1995c). Third, knowledge of $\lambda_{2}$ is required to identify $\psi$. Fourth, efficiency may be lost because $\lambda_{2}$ contains useful information about $\lambda_{1}$, as with classical cross-equation restrictions. In the current paper, the first and second types are most relevant. 


\subsection{Granger Non-causality and Strong Exogeneity}

Granger non-causality is one of two conditions required for strong exogeneity, which bears on conditional impulse response analysis (Section 5) and conditional forecasting inter alia. Granger causality is defined as the presence of feedback from one variable to another, with Granger non-causality defined as the absence of such feedback.

Definition 2 Suppose that the marginal density $f_{z}(\cdot)$ does not depend on $Y_{t-1}$, i.e., $f_{z}\left(z_{t} \mid X_{t-1}, \cdot\right)=f_{z}\left(z_{t} \mid Z_{t-1}, \cdot\right)$. Then, $y$ does not Granger cause $z$. [See Granger (1969) and Engle, Hendry, and Richard (1983, Definition 2.1).]

One set of variables (here, $y$ ) does not Granger-cause the remaining variables (here, $z$ ) if, given the information set available, deleting the history of the former set of variables does not alter the joint distribution of the remaining variables.

Unlike weak exogeneity, Granger causality does not involve parameters of interest and so is not related to their estimation. Indeed, Granger non-causality is neither necessary nor sufficient for weak exogeneity. Granger non-causality in combination with weak exogeneity, however, defines strong exogeneity.

Definition $3 z_{t}$ is strongly exogenous for the parameters of interest $\psi$ if $z_{t}$ is weakly exogenous for $\psi$ and if $f_{z}\left(z_{t} \mid X_{t-1}, \cdot\right)=f_{z}\left(z_{t} \mid Z_{t-1}, \cdot\right)$. [See Engle, Hendry, and Richard (1983, Definition 2.6).]

Strong exogeneity permits conditional forecasting from the conditional model without loss of information. That is, forecasts of $z$ over several periods may be constructed, and then forecasts for $y$ are generated from the conditional model, conditional on that set of forecasts for $z$. If $y$ did Granger-cause $z$, then forecasts for $y$ and $z$ would need to be constructed together, one period at a time, or else risk losing valuable information from feedback.

The preceding discussion of weak and strong exogeneity assumes parameter constancy, although abundant empirical evidence indicates the presence of regime shifts and structural changes in the economy. Hence, the next subsection extends the concept of exogeneity to allow for the presence of parameter nonconstancies, such as might result from changes in economic policy rules.

\subsection{Invariance and Super Exogeneity}

Even if the parameters of $f_{y \mid z}\left(y_{t} \mid z_{t}, X_{t-1}, \lambda_{1}\right)$ and $f_{z}\left(z_{t} \mid X_{t-1}, \lambda_{2}\right)$ are variation free, $\lambda_{1}$ still may change as $\lambda_{2}$ alters. The explanation turns on the relationship between $\lambda_{1}$ and $\lambda_{2}$ and on their dependence on $\left\{\zeta_{t}\right\}$ through interventions, at what is sometimes called the level of deep parameters. Specifically, the policy agency determines the marginal process $D_{z}\left(z_{t} \mid X_{t-1}, \zeta_{2 t}\right)$, even though it decides policy on the basis of its models rather than the DGP. Changes in $\zeta_{2 t}$ alter $\lambda_{2}$, and those changes may or may 
not alter $\lambda_{1}$. The presence or lack of invariance to a class of interventions is tied to a third concept of exogeneity, super exogeneity, as discussed later in this subsection. With super exogeneity, conditional policy simulations involve no loss of information relative to simulations of the variables' joint distribution.

A parameter intervention at time $t$ affecting the DGP $D_{x}\left(x_{t} \mid X_{t-1}, \zeta_{t}\right)$ is defined as any action $a_{t}$ by an agent, where that action alters last period's parameter value $\zeta_{t-1}$ to become this period's parameter value $\zeta_{t}\left[\equiv w\left(a_{t}, \zeta_{t-1}\right)\right.$, say]. If no intervention occurs, then $\zeta_{t}=\zeta_{t-1}$. Let $\mathcal{C}_{\zeta}(t)\left[\equiv\left\{a_{t}: \zeta_{t}=w\left(a_{t}, \zeta_{t-1}\right)\right\}\right]$ be the set of interventions at time $t$ on $D_{x}\left(x_{t} \mid X_{t-1}, \cdot\right)$ that potentially affect $\zeta_{t}$, and denote the set of such interventions over the full sample as $\mathcal{C}_{\zeta}\left[\equiv\left\{\mathcal{C}_{\zeta}(t), t=1, \ldots, T\right\}\right]$. Possible interventions include changes to monetary, fiscal, and exchange-rate policy rules, deregulation, financial and technological innovation, nationalization, and war. Because the DGP is the economic mechanism, its parameterization can be affected by intervention. Indeed, the aim of many economic policies is precisely to affect the DGP. Such interventions may consequentially affect an econometric model. Here, those of most relevance are changes in the marginal process that are enacted by a policy agency controlling $\zeta_{2 t}$, with the associated class of interventions denoted by $\mathrm{C}_{2}$.

The conditional model's parameters $\lambda_{1}$ may alter as $\zeta_{2 t}$ varies within the class of interventions $\mathcal{C}_{2}$. Engle and Hendry (1993) and Section 3 below consider derived changes in $\zeta_{1 t}$, such as would occur under the Lucas critique. (Policies involving direct changes in $\zeta_{1 t}$ are more difficult to analyze and are not considered here.) Conversely, the model parameters $\lambda_{1}$ may be invariant to a class of interventions $\mathcal{C}_{2}$.

Definition $4 \lambda_{1}$ is invariant to a class of interventions $\mathcal{C}_{2}$ if $\lambda_{1}$ is constant over $\mathcal{C}_{2}$. [See Engle, Hendry, and Richard (1983, Definitions 2.7 and 2.8).]

Because economies undergo numerous changes, it is important for econometric modeling that some of the economies' features be invariant to those changes. Without such invariance, econometric modeling and economic policy analysis using econometric models would be of limited value. Moreover, the invariance of $\lambda_{1}$ is central to obtaining reliable policy simulations (or counterfactual experiments), in which the path of some policy instrument $z$ is specified and the path of a target variable $y$ is calculated from the conditional econometric model $f_{y \mid z}\left(y_{t} \mid z_{t}, X_{t-1}, \lambda_{1}\right)$. Because $\lambda_{1}$ is unknown, the weak exogeneity of $z_{t}$ for the parameters of interest is typically required for efficient estimation from the conditional distribution alone. Reliable policy simulation thus requires the combination of weak exogeneity and invariance, which Engle, Hendry, and Richard (1983) define as super exogeneity.

Definition $5 z_{t}$ is super exogenous for the parameters of interest $\psi$ if $z_{t}$ is weakly exogenous for $\psi$ and if $\lambda_{1}$ is invariant to $\mathcal{C}_{2}$. [See Engle, Hendry, and Richard (1983, Definition 2.9).] 
Under super exogeneity, policy actions affect $\zeta_{2 t}$, thus altering the marginal model's parameters $\lambda_{2}$ and the path of the policy variable $z$. Those policy actions do not affect the conditional model's parameters $\lambda_{1}$, although outcomes for $y$ depend on the hypothesized path for the policy variable $z$ through the conditional model itself. Thus, under super exogeneity, policy can and (in general) does affect agent behavior: it does so through the variables entering the conditional model, albeit not through the parameters of that model. Finally, $y$ may Granger-cause $z$ even if $z_{t}$ is super exogenous.

\section{Cointegration and Exogeneity}

This section elaborates on the concepts of weak exogeneity, Granger non-causality, strong exogeneity, invariance, and super exogeneity for a commonly used class of econometric model - the finite-order vector autoregression (VAR). The cointegrated (or reduced rank) VAR has been used successfully in many areas of economics, and it appears capable of capturing some of the potential relationships among economic time series. Section 2.1 discusses the VAR itself. Sections 2.2 and 2.3 consider specific implications of weak exogeneity and Granger causality for that VAR, whereas Section 2.4 highlights more general aspects of economic policy analysis. Sections 3, 4 , and 5 focus on implications of exogeneity for three central issues in policy analysis: the Lucas critique, model inversion, and impulse response analysis.

\subsection{A Cointegrated Vector Autoregression}

A VAR has several equivalent representations that are valuable for understanding the interactions between exogeneity, cointegration, and economic policy analysis. To start, the levels form of the $s^{\text {th }}$-order Gaussian VAR for $x$ is:

$$
x_{t}=K q_{t}+\sum_{j=1}^{s} A_{j} x_{t-j}+\varepsilon_{t} \quad \varepsilon_{t} \sim \operatorname{IN}_{N}(0, \Sigma),
$$

where $K$ is an $N \times N_{0}$ matrix of coefficients of the $N_{0}$ deterministic variables $q_{t}$; the $A_{j}$ are $N \times N$ matrices of autoregressive coefficients; and $\varepsilon_{t}$ is a vector of $N$ unobserved, jointly normal, sequentially independent errors with mean zero and (constant) covariance matrix $\Sigma$. This subsection examines some properties of (4), first transforming it to $\mathrm{I}(0)$ space with mean-zero variables. For expositional convenience, $x$ is restricted to be (at most) integrated of order one, denoted $\mathrm{I}(1)$, where an $\mathrm{I}(j)$ variable requires $j^{\text {th }}$ differencing to make it stationary. Again, for expositional convenience, the system is often first-order $(s=1)$ or second-order $(s=2)$ with a (possibly zero) intercept $\delta$ as the only deterministic variable $\left(\delta=K q_{t}\right)$. See Johansen (1992c, 1992d, 1992e) and Juselius (1998, this issue) for theoretical and empirical analyses of cointegrated $\mathrm{I}(2)$ 
variables. Normality is also a convenient assumption, but one not required by the framework of Section 1.

Suppose that the VAR in (4) is second-order, has an intercept as its only deterministic variable, and has $r(r<N)$ cointegrating relations $\beta^{\prime} x_{t}$, defined as nonzero linear combinations of $x_{t}$ that are $\mathrm{I}(0)$. That VAR can be written as the vector equilibrium-correction model,

$$
\Delta x_{t}=\delta+\alpha \beta^{\prime} x_{t-1}+\Gamma \Delta x_{t-1}+\varepsilon_{t}
$$

The first difference operator $\Delta$ equals $1-L$, where $L$ is the lag operator such that $L x_{t}=x_{t-1} ; \alpha$ and $\beta$ are $N \times r$ matrices of rank $r$ such that $\alpha \beta^{\prime}=A_{1}+A_{2}-I_{N}$; and $\Gamma=-A_{2}$. See Johansen (1988, 1991, 1992b, 1995), Johansen and Juselius (1990), Banerjee, Dolado, Galbraith, and Hendry (1993), and Hendry (1995a) for key developments of and discussions on this class of cointegrated system. Identification restrictions must be imposed to ensure uniqueness of $\alpha$ and $\beta$. For the correct choice of $r$, the model in (5) is in $\mathrm{I}(0)$ space, so inference about the parameters $\delta, \alpha, \Gamma$, and $\Sigma$ can be conducted using conventional procedures.

The VAR in (5) can be usefully rewritten with zero-mean variables. Suppose that, in steady state, the underlying variables grow at a rate $\gamma$, defined as $\mathcal{E}\left(\Delta x_{t}\right)$, where $\mathcal{E}(\cdot)$ is the expectations operator. Taking expectations across (5) and re-arranging, the long-run solution of the system is:

$$
\alpha \mathcal{E}\left(\beta^{\prime} x_{t}\right)=\left(I_{N}-\Gamma\right) \gamma-\delta
$$

Defining the equilibrium mean $\mathcal{E}\left(\beta^{\prime} x_{t}\right)$ as $\mu$ implies:

$$
\delta=\left(I_{N}-\Gamma\right) \gamma-\alpha \mu \text {. }
$$

Thus, adding and subtracting $\gamma$ and $\mu$ in (5) yields an expression in which all terms have zero means:

$$
\left(\Delta x_{t}-\gamma\right)=\alpha\left(\beta^{\prime} x_{t-1}-\mu\right)+\Gamma\left(\Delta x_{t-1}-\gamma\right)+\varepsilon_{t}
$$

If $\delta$ lies in the cointegration space $(\delta=-\alpha \mu)$, then $\gamma=0$ and so $x$ has a growth rate of zero.

The $\mathrm{I}(0)$ system in $(8)$ can be re-expressed as a VAR in the $N+r$ zero-mean variables $\left(\Delta x_{t}-\gamma\right)$ and $\left(\beta^{\prime} x_{t-1}-\mu\right)$, similar to Hendry and Mizon (1993, equation $\left.(5)\right)$ :

$$
\left[\begin{array}{c}
\left(\Delta x_{t}-\gamma\right) \\
\left(\beta^{\prime} x_{t-1}-\mu\right)
\end{array}\right]=\left[\begin{array}{cc}
\left(\alpha \beta^{\prime}+\Gamma\right) & \alpha \\
\beta^{\prime} & I_{r}
\end{array}\right]\left[\begin{array}{c}
\left(\Delta x_{t-1}-\gamma\right) \\
\left(\beta^{\prime} x_{t-2}-\mu\right)
\end{array}\right]+\left[\begin{array}{c}
\varepsilon_{t} \\
0
\end{array}\right]
$$

noting that $\beta^{\prime} \gamma=0$. Although the errors in this $(N+r)$-dimensional system have a singular distribution, (9) is convenient for retaining relevant transformations of variables and for generating multi-step ahead forecasts of the transformed variables. 
Moreover, the empirical example in Section 6 uses it to calculate the impulse responses of the cointegrating combinations as well as of the growth rates. Many mappings of (9) into $N$ dimensions yield a nonsingular distribution. Some are interpretable as $(N-r)$ common trends and $r$ cointegrating vectors, but they are not unique.

\subsection{Long-run Weak Exogeneity}

Cointegrating vectors are often parameters of interest, and weak exogeneity of $z_{t}$ for them can aid in conducting inference. Johansen and Juselius (1990), Davidson and Hall (1991), Boswijk (1992, 1995), Dolado (1992), Johansen (1992a, 1992e), Urbain (1992), Hendry and Mizon (1993), and Hendry (1995c) discuss testing weak exogeneity in cointegrated systems. From those papers, this subsection extracts two key results, presented as Lemmas 1 and 2; and it shows how the choice of parameters of interest affects the conditions for weak exogeneity.

Partitioning of the variables and matrices in (5) facilitates discussing weak exogeneity, Granger causality, and their relation to policy analysis. With partitioning, (5) is:

$$
\begin{aligned}
{\left[\begin{array}{l}
\Delta y_{t} \\
\Delta z_{t}
\end{array}\right]=} & {\left[\begin{array}{l}
\delta_{1} \\
\delta_{2}
\end{array}\right]+\left[\begin{array}{l}
\alpha_{1} \\
\alpha_{2}
\end{array}\right] \beta^{\prime} x_{t-1}+\left[\begin{array}{l}
\Gamma_{1} \\
\Gamma_{2}
\end{array}\right] \Delta x_{t-1}+\left[\begin{array}{l}
\varepsilon_{1 t} \\
\varepsilon_{2 t}
\end{array}\right] } \\
= & {\left[\begin{array}{l}
\delta_{1} \\
\delta_{2}
\end{array}\right]+\left[\begin{array}{ll}
\alpha_{11} & \alpha_{12} \\
\alpha_{21} & \alpha_{22}
\end{array}\right]\left[\begin{array}{ll}
\beta_{11}^{\prime} & \beta_{12}^{\prime} \\
\beta_{21}^{\prime} & \beta_{22}^{\prime}
\end{array}\right]\left[\begin{array}{l}
y_{t-1} \\
z_{t-1}
\end{array}\right] } \\
& +\left[\begin{array}{ll}
\Gamma_{11} & \Gamma_{12} \\
\Gamma_{21} & \Gamma_{22}
\end{array}\right]\left[\begin{array}{l}
\Delta y_{t-1} \\
\Delta z_{t-1}
\end{array}\right]+\left[\begin{array}{l}
\varepsilon_{1 t} \\
\varepsilon_{2 t}
\end{array}\right] .
\end{aligned}
$$

Parameters are partitioned by variable and (for $\alpha$ and $\beta$ ) by cointegrating vector. Specifically, $\beta^{\prime}$ is divided by row into two subsets of cointegrating vectors, $\beta_{1}^{\prime}$ and $\beta_{2}^{\prime}$, which are themselves partitioned by variable as $\left(\beta_{11}^{\prime}: \beta_{12}^{\prime}\right)$ and $\left(\beta_{21}^{\prime}: \beta_{22}^{\prime}\right)$.

The VAR in (10) may be reparameterized as the conditional and marginal distributions in (3):

$$
\begin{aligned}
\Delta y_{t}= & \left(\delta_{1}-D \delta_{2}\right)+\left(\alpha_{1}-D \alpha_{2}\right) \beta^{\prime} x_{t-1}+D \Delta z_{t}+\left(\Gamma_{1}-D \Gamma_{2}\right) \Delta x_{t-1}+v_{1 t} \\
= & \left(\delta_{1}-D \delta_{2}\right)+\left[\left(\alpha_{11} \beta_{11}^{\prime}+\alpha_{12} \beta_{21}^{\prime}\right)-D\left(\alpha_{21} \beta_{11}^{\prime}+\alpha_{22} \beta_{21}^{\prime}\right)\right] y_{t-1} \\
& +\left[\left(\alpha_{11} \beta_{12}^{\prime}+\alpha_{12} \beta_{22}^{\prime}\right)-D\left(\alpha_{21} \beta_{12}^{\prime}+\alpha_{22} \beta_{22}^{\prime}\right)\right] z_{t-1} \\
& +D \Delta z_{t}+\left(\Gamma_{11}-D \Gamma_{21}\right) \Delta y_{t-1}+\left(\Gamma_{12}-D \Gamma_{22}\right) \Delta z_{t-1}+v_{1 t} \\
\Delta z_{t}= & \delta_{2}+\alpha_{2} \beta^{\prime} x_{t-1}+\Gamma_{2} \Delta x_{t-1}+\varepsilon_{2 t} \\
= & \delta_{2}+\left(\alpha_{21} \beta_{11}^{\prime}+\alpha_{22} \beta_{21}^{\prime}\right) y_{t-1}+\left(\alpha_{21} \beta_{12}^{\prime}+\alpha_{22} \beta_{22}^{\prime}\right) z_{t-1} \\
& +\Gamma_{21} \Delta y_{t-1}+\Gamma_{22} \Delta z_{t-1}+\varepsilon_{2 t},
\end{aligned}
$$

where $D=\Sigma_{12} \Sigma_{22}^{-1}, v_{1 t}=\varepsilon_{1 t}-D \varepsilon_{2 t}$, and so $\operatorname{Var}\left(v_{1 t}\right) \equiv \Omega_{11}=\Sigma_{11}-\Sigma_{12} \Sigma_{22}^{-1} \Sigma_{21}$. We assume that $\beta_{1}$ and $\beta_{2}$ each contain at least one cointegrating vector $\left(r_{1}>0, r_{2}>0\right)$, 
that $\beta_{1}$ enters the first block $\left(\alpha_{11} \neq 0\right)$, and that $D \neq 0$ (implying contemporaneous correlation between $y$ and $z$ ), as these assumptions generate situations of particular interest.

Different conditions for the long-run weak exogeneity of $z_{t}$ exist, depending upon the parameters of interest.

Lemma 1 Suppose that the parameters of interest are $\beta$. Then, $z_{t}$ is weakly exogenous for $\beta$ if and only if $\alpha_{2}=0$ (i.e., $\alpha_{21}=0$ and $\alpha_{22}=0$ ). [See Johansen (1992a).]

The condition $\alpha_{2}=0$ ensures that $\beta$ does not appear in the marginal distribution for $z_{t}$. However, the parameters of interest might be only a subset of the cointegrating vectors, in which case other conditions also obtain weak exogeneity.

Lemma 2 Suppose that the parameters of interest are $\beta_{1}$. Then, $z_{t}$ is weakly exogenous for $\beta_{1}$ if $\alpha_{21}=0$ and $\left(\alpha_{12}-D \alpha_{22}\right)=0$. [See Hendry and Mizon (1993).]

These conditions ensure that $\beta_{1}$ enters the conditional model but not the marginal one. These conditions are sufficient but not necessary; and Ericsson (1995, Section 3.1) presents an alternative set of sufficient conditions for the weak exogeneity of $z_{t}$ for $\beta_{1}$, noting that $\Sigma_{12}$ (and so $D$ ) need not be zero in those conditions. Harbo, Johansen, Nielsen, and Rahbek (1998, Section 5, this issue) illustrate empirically how the choice of parameters of interest can affect which variables are weakly exogenous. Equations (11)-(12) also indicate how the choice of policy rule can affect weak exogeneity. For instance, responses by the policy variable $\Delta z_{t}$ to past disequilibria $\left(\beta_{1}^{\prime} x_{t-1}-\mu_{1}\right)$ induce a failure of weak exogeneity, which could imply inefficient or inconsistent inference on $\beta_{1}$ if estimation is of the conditional model alone.

Empirically, weak exogeneity in cointegrated systems arises with considerable regularity, as documented by Ericsson and Irons's (1995, pp. 298-301) literature search on super exogeneity and by the empirical articles reprinted in Ericsson and Irons (1994). Depending upon how many variables are included in $z$, weak exogeneity may entail a conditional subsystem or a conditional single-equation model. Juselius (1998, this issue) and Section 6 below are of the first type, whereas de Brouwer and Ericsson (1998, this issue) is of the second. Even without weak exogeneity, single-equation modeling may be feasible by treating the system estimates of the cointegrating vector(s) as given; see Juselius (1992), Durevall (1998, this issue), and Metin (1998, this issue).

\subsection{Granger Causality}

The conditions for Granger non-causality in (10) can be stated simply. 
Lemma 3 In (10), $y$ does not Granger-cause $z$ if and only if $\left(\alpha_{21} \beta_{11}^{\prime}+\alpha_{22} \beta_{21}^{\prime}\right)=0$ and $\Gamma_{21}=0$.

Suppose that the policy instruments are $z$ and that the target variables of economic policy are $y$. These conditions for Granger non-causality are unlikely to be satisfied in practice because past values of target variables typically influence the present choice of the policy instruments' values. For example, recent past inflation is likely to influence the tightness of monetary and fiscal policy. Actual policy simulations may or may not assume such feedback: all the policy simulations in the papers in Bryant, Henderson, Holtham, Hooper, and Symansky (1988) assume Granger non-causality in the policy rule (see their p. 29), whereas the papers in Bryant, Hooper, and Mann (1993) focus on the presence of feedbacks in the policy rule (see their pp. 13, 20).

Economic policy typically assumes that changes in the instruments $z$ affect the targets $y$. The converse has immediate repercussions.

Lemma 4 In (10), $z$ does not Granger-cause $y$ if and only if $\left(\alpha_{11} \beta_{12}^{\prime}+\alpha_{12} \beta_{22}^{\prime}\right)=0$ and $\Gamma_{12}=0$.

Without Granger causality from instruments to targets, policy is unlikely to be effective. The conditions for Granger causality, which are directly relevant for assessing the feasibility of economic policy, are features of the joint distribution of $y_{t}$ and $z_{t}$, conditional on their past values. These conditions are unrelated to those for weak exogeneity, which pertains to statistical inference in a conditional model. For further details on testing causality in I(1) systems, see Mosconi and Giannini (1992) and Toda and Phillips (1993, 1994).

\subsection{Policy, the DGP, and the Econometric Model}

Often, the objective of economic policy is to shift the mean of the target variables $y$ to a desired value (or within a desired range) by changing the instruments $z$. In such a situation, one set of sufficient conditions for reliable policy analysis is that the econometric model coincides with the DGP both before and after the policy intervention, and that the policy is feasible. The first of these conditions is unlikely to be fulfilled in practice, and no criteria currently exist for determining whether or not it is fulfilled. Consequently, necessary conditions with testable implications are typically examined. The hypotheses of exogeneity, causality, and invariance are testable in econometric models, so important aspects of conditional econometric models may be assessed prior to their use in policy analysis.

The hypotheses of exogeneity, causality, and invariance have implications for policy analysis with a macro-econometric model, even if that model is treated as a deterministic, numerical, accounting structure. Causal links from the instruments to the targets are essential for policy to have an effect; and unchanging parameters 
are needed for that effect to be as anticipated. On the latter, a model might well perform according to its established operational characteristics when forecasting over a short horizon or analyzing small policy adjustments. For active interventions such as financial deregulation, new taxes, and monetary union, more stringent criteria are likely to be required. Tests of exogeneity help assess how well a model will predict the actual outcome.

The following conditions are typically necessary for such policy analysis to be of value.

1. The policy instruments and the targets have genuine causal links; see Granger and Deutsch (1992).

2. The model represents the economy closely enough in relevant attributes that its policy predictions reasonably match outcomes. Empirically testable conditions include congruency (the model is coherent with all available information) and encompassing (the model is undominated by alternative models); see Hendry (1995a) and Bontemps and Mizon (1997).

3. The change in policy does not alter the econometric model in a self-contradictory way; see Lucas (1976).

4. The policy experiment is feasible in reality and within the econometric model.

5. The policy instruments are manipulable, in that the policy agency can set the instruments to those values desired for the policy experiment.

The econometric concepts of causality, congruence, encompassing, exogeneity, and invariance are associated with conditions 1,2 , and 3 . Under condition 1 , moving $y$ by changing $z$ may occur in three distinct ways: contemporaneously, with a delay, and in the long run, as (11) clarifies. The applicability of policy, however, depends on the actual causal links, and not on the apparent links in the econometric formulation. Although such a point seems obvious, models are often applied to policy issues without explicit testing of their policy relevance. Tests of super exogeneity may shed light on their relevance by focusing on the invariance of the econometric relation under historical interventions and on the significance of the claimed connections. Condition 3 leads to Section 3, immediately below. Feasibility (in condition 4) concerns the relationship between the policy experiment, the DGP, and the econometric model; and manipulability (in condition 5) is a feature of the policy instruments. Manipulability differs from controllability, which has a specific meaning in the engineering literature. Here, manipulability corresponds to altering $\zeta_{2 t}$ in the marginal distribution of $z_{t}$, as might arise if $\zeta_{2 t}$ were the base rate set by a central bank and $z_{t}$ were a very shortterm interest rate. The same policy might be infeasible for a long-term interest rate if international arbitrage determined the latter. 


\section{The Lucas Critique}

Lucas (1976) criticizes using an econometric model for policy analysis if implementing the policy under evaluation would alter the structure that the model was attempting to capture. Lucas considers examples in which agents' expectations of policy behavior enter into their optimization problem, and so parameters relating to policymakers' rules appear in the agents' first-order conditions. Specifically, if agents form modelbased expectations about $z$ when planning $y$, then $\lambda_{1}$ depends on $\lambda_{2}$, and $\lambda_{1}$ will change if policy alters $\lambda_{2}$ through changes in $\zeta_{2 t}$. Without super exogeneity, such unmodeled changes in $\lambda_{1}$ are likely to confound conditional policy analysis. More generally, behavioral parameters may not be invariant to some policy interventions. Simply treating the econometric model's coefficients as constant does not ensure their constancy when a policy is implemented. Even if weak exogeneity holds, parameters may change when policy rules alter. In essence, the Lucas critique questions whether or not an econometric model isolates invariants of the economic process. This section briefly reviews recent research on the Lucas critique, drawing on Section 1.4. See Frisch (1938), Haavelmo (1944), and Marschak (1953) inter alia for earlier discussions on invariance and on what is now called the Lucas critique.

The Lucas critique concerns two related properties of the conditional and marginal models' parameters: constancy and invariance. As suggested by Gordon (1976, pp. 48-49) and developed by Hendry (1988) and Engle and Hendry (1993), these properties provide two approaches for testing the Lucas critique.

1. Test for the constancy of $\lambda_{1}$ and of $\lambda_{2}$. If $\lambda_{1}$ is constant but $\lambda_{2}$ is not, then $\lambda_{1}$ is invariant to the interventions that occurred, so the Lucas critique could not apply. [See Hendry (1988).]

2. Develop the marginal model until its parameters are empirically constant. For instance, model the way in which $\lambda_{2}$ varies over time by adding dummies or other variables to the marginal model. Then, test for the significance of those dummies or other variables in the conditional model. Their insignificance in the conditional model demonstrates the invariance of $\lambda_{1}$ to the modeled interventions, whereas their significance shows the dependence of $\lambda_{1}$ on $\lambda_{2}$. [See Engle and Hendry (1993).]

Provided that the parameters of interest can be retrieved from $\lambda_{1}$ alone, the invariance of $\lambda_{1}$ implies the super exogeneity of $z_{t}$.

The empirical presence of super exogeneity refutes the Lucas critique in practice. Under super exogeneity, expectational models such as those proposed by Lucas could not explain why $\lambda_{1}$ remained constant while $\lambda_{2}$ changed, and so could not adequately explain the data. The Lucas critique as a possibility theorem is not empirically refutable; but, through that theorem, its assumptions generate testable implications. Whether the Lucas critique applies for a specific economic relationship is thus an empirical issue. 
A literature search in Ericsson and Irons (1995) of articles citing Lucas (1976) finds virtually no substantiating evidence for the empirical relevance of the Lucas critique. In an additional literature search of articles citing Engle, Hendry, and Richard (1983), Hendry (1988), and Engle and Hendry (1993), Ericsson and Irons (1995) uncover numerous models with empirical super exogeneity, with those models spanning many sectors of several countries' economies. Economically, super exogeneity may arise if agents form expectations without using models, e.g., because information is costly or because the benefits from model-based expectations are low. Hendry (1988; 1995a, Chapters 14 and 15), Favero and Hendry (1992), Engle and Hendry (1993), and Ericsson and Irons (1995) provide further discussion.

Fundamental difficulties may arise if policy experiments violate pre-existing exogeneity conditions. Empirically, policy might alter the exogeneity of a variable, as perhaps in the switch from fixed to floating exchange rates. A conditional model is unlikely to be reliable in such a situation, at least not without more information about its properties than is usually provided. Moreover, policy analysis might make a counterfactual assumption about exogeneity. Section 4 considers one such situation - inversion of an econometric equation - and shows what problems arise.

\section{Inversion of an Econometric Equation}

An econometric equation is sometimes inverted to determine the settings of policy variables $z$ as a function of target values for $y$. For example, money-demand equations are often inverted to obtain the price level, transforming $M=k P I$ to $P=M /(k I)$ in a standard notation. Inverting money-demand equations to obtain prices is common among monetarists and macroeconomists, whereas inversion to obtain the interest rate (implicit in $k$ ) is common among macro-modelers. For examples, see Friedman and Schwartz (1982, Chapter 2), Hallman, Porter, and Small (1991, pp. 842ff), and Barro (1997, pp. 184ff, 278ff) on the former, and Fair (1984, pp. 319-323) and Edison, Marquez, and Tryon (1987, pp. 130-131) on the latter. Inversion may occur prior to or after estimation: depending upon the DGP, each may have unfortunate consequences for policy analysis, as Sections 4.1 and 4.2 discuss. Detailed expositions appear in Hendry (1985), Ericsson (1992, Section 2C), and Engle and Hendry (1993; 1994, Appendix).

\subsection{Inversion Prior to Estimation}

Inversion prior to estimation can imply parameter nonconstancy, the loss of weak exogeneity, alteration of the inverted coefficient, and invalid exclusion restrictions. Such inversion corresponds to an alternative factorization for the joint density (3), 
namely:

$$
f_{x}\left(y_{t}, z_{t} \mid X_{t-1}, \theta_{t}\right)=f_{z \mid y}\left(z_{t} \mid y_{t}, X_{t-1}, \phi_{1 t}\right) \cdot f_{y}\left(y_{t} \mid X_{t-1}, \phi_{2 t}\right),
$$

where $f_{z \mid y}(\cdot)$ is the conditional density of $z_{t}$ given $y_{t}$ and $X_{t-1}, f_{y}(\cdot)$ is the marginal density of $y_{t}$ given $X_{t-1}$, the corresponding parameters are $\phi_{t} \equiv\left(\phi_{1 t}^{\prime}: \phi_{2 t}^{\prime}\right)^{\prime}=g^{*}\left(\theta_{t}\right)$, the function $g^{*}(\cdot)$ is a one-to-one mapping from $\theta$ to $\phi$, and $\lambda_{2}$ (and so $\theta$ ) is allowed to be nonconstant $\left(\lambda_{2}=\lambda_{2 t}\right)$. The conditional model $f_{y \mid z}(\cdot)$ in the original factorization (3) is assumed constant, although its affiliated marginal model $f_{z}(\cdot)$ is nonconstant through $\lambda_{2 t}$. Because $\left(\phi_{1 t}: \phi_{2 t}\right)$ depends upon all elements of $\left(\lambda_{1}: \lambda_{2 t}\right)$ through $\theta_{t}$, in general neither the conditional model nor the marginal model in (13) has constant parameters. This lack of invariance poses problems for policy analysis. It also provides a modified approach for testing super exogeneity and causality, as Hoover and Sheffrin (1992) propose.

A dynamic bivariate normal distribution highlights specific difficulties of inversion for policy analysis. Suppose that the original factorization, corresponding to (3), obtains:

$$
\begin{aligned}
& y_{t}=D z_{t}+v_{1 t} \\
& z_{t}=a_{2 t}+A_{2}(L) x_{t-1}+\varepsilon_{2 t},
\end{aligned}
$$

where $\mathcal{E}\left(v_{1 t} \varepsilon_{2 t}^{\prime}\right)=0$ by construction, $a_{2 t}$ is a variable that can be set by the policy agency, $A_{2}(\cdot)$ is a $k \times N$ matrix polynomial of order $s, A_{2}(L) x_{t-1}$ captures the dynamics in (15), and $m=k=1$; cf. (4). The conditional model (14) thus omits $a_{2 t}$ and dynamics, which are testable exclusions.

The parameterization $\left(D, \Omega_{11}, A_{2}(\cdot), \Sigma_{22}\right)$ in (14)-(15) sustains the weak exogeneity of $z_{t}$ for $\left(D, \Omega_{11}\right)$ in $(14)$. If $\left(D, \Omega_{11}\right)$ is also invariant to interventions in $\left(A_{2}(\cdot), \Sigma_{22}\right)$, then $z_{t}$ is super exogenous for $\left(D, \Omega_{11}\right)$. If $A_{21}(L)=0$ and $z_{t}$ is weakly exogenous for $\left(D, \Omega_{11}\right)$, then $z_{t}$ is strongly exogenous for $\left(D, \Omega_{11}\right)$.

Direct inversion of the conditional model (14) yields:

$$
z_{t}=D^{-1} y_{t}-D^{-1} v_{1 t}
$$

Although (16) is algebraically correct, (16) is not a conditional model for $z_{t}$. That (reverse) conditioning, as in (13), actually obtains:

$$
\begin{aligned}
z_{t} & =B_{0} a_{2 t}+B_{0} A_{2}(L) x_{t-1}+B_{1} y_{t}+v_{2 t} \\
y_{t} & =D a_{2 t}+D A_{2}(L) x_{t-1}+\varepsilon_{1 t},
\end{aligned}
$$

where $\mathcal{E}\left(v_{2 t} \varepsilon_{1 t}^{\prime}\right)=0$ from conditioning, $B_{0}=I_{k}-B_{1} D, B_{1}=\Sigma_{22} D^{\prime}\left(\Omega_{11}+D \Sigma_{22} D^{\prime}\right)^{-1}$, and $\operatorname{Var}\left(v_{2 t}\right) \equiv \Omega_{22}=\Sigma_{22}-\Sigma_{21} \Sigma_{11}^{-1} \Sigma_{12}$.

In $(17), y_{t}$ is not weakly exogenous for either $\left(B_{0}, B_{1}\right)$ or the original parameters $\left(D, \Omega_{11}\right)$ because the six sets of parameters $\left(B_{0}, B_{1}, A_{2}(\cdot), \Omega_{22}, D, \Sigma_{11}\right)$ in the reparameterized system (17)-(18) are linked by cross-equation restrictions. Additionally, 
$B_{1} \neq D^{-1}$ unless $\Omega_{11}=0$; or, equivalently, the coefficient on $y_{t}$ in the conditional model (17) is not equal to the coefficient on $y_{t}$ in the inverted model (16) unless (16) is an identity. Finally, the conditional model (17) includes $a_{2 t}$ and $X_{t-1}^{t-s}$, whereas the inverted equation (16) excludes those variables. This difference arises because the original conditional model (14) explicitly excludes $a_{2 t}$ and $X_{t-1}^{t-s}$. If $a_{2 t}$ and $X_{t-1}^{t-s}$ entered (14) unrestrictedly, either direction of conditioning could sustain weak exogeneity for some choice of parameters of interest, and weak exogeneity would not be testable directly. Weak exogeneity could be tested indirectly through testing for super exogeneity (as in Section 3), and an incorrect choice of factorization could still induce poor policy recommendations through violation of super exogeneity.

\subsection{Inversion After Estimation}

Inversion after estimation also affects model use, even if such inversion does not alter the underlying equation parameters. Estimated models are sometimes treated as deterministic accounting algorithms and their equations manipulated accordingly, as when target variables in a model are "exogenized". The appropriateness of doing so depends upon whether or not the underlying stochastic structure is preserved. The unconditional expectation of (14) illustrates:

$$
\mathcal{E}\left(y_{t}\right)=D \mathcal{E}\left(z_{t}\right)
$$

If $z_{t}$ is controlled by the policy agency and $D \neq 0$, inversion of (19) permits calculating the value $\hat{z}_{t}$ needed to achieve the desired target $\hat{y}_{t}$ in expectation:

$$
\hat{z}_{t}=D^{-1} \mathcal{E}\left(\hat{y}_{t}\right)
$$

Choosing that $\hat{z}_{t}$ delivers $\hat{y}_{t}$ on average, assuming super exogeneity of $z_{t}$ for $D$ under that intervention.

Although closely related to (20), direct inversion of (14) could alter the covariance structure of the system. That inversion is:

$$
z_{t}=D^{-1}\left(y_{t}-v_{1 t}\right)
$$

where $\mathcal{E}\left(z_{t} v_{1 t}^{\prime}\right)=0$ in fact, and $\mathcal{E}\left(y_{t} v_{1 t}^{\prime}\right) \neq 0$. Relatedly, for nonlinear systems, unconditional expectations corresponding to (19) are often analytically intractable and so are approximated by averaging stochastic simulations. If inversion precedes simulation, then the effect is equivalent to (21). To preserve the covariance structure, a procedure might fix $z_{t}$ at a trial value and simulate $\mathcal{E}\left(y_{t}\right)$, iterating on $z_{t}$ until the desired (average) target value for $y_{t}$ results.

If $y$ and $z$ are $\mathrm{I}(1)$ and cointegrated, inversion of the cointegrating relation might seem innocuous because the particular normalization in a cointegrating regression need not matter (at least asymptotically), even prior to estimation; see Engle and 
Granger (1987). Inversion does not alter the direction of causality, however, so the inverted relation need not be economically interpretable. Consider a simple, mainly static version of the conditional and marginal models in (11)-(12):

$$
\begin{aligned}
y_{t} & =b^{\prime} z_{t}+v_{1 t} \\
\Delta z_{t} & =\varepsilon_{2 t},
\end{aligned}
$$

where $b$ is nonzero and is defined such that $\beta^{\prime}=\left(1:-b^{\prime}\right)$. This system's cointegrating relation implies $\mathcal{E}\left(y_{t}-b^{\prime} z_{t}\right)=0$. A cointegrating relation, however, is simply that - a relation - and it does not specify causal direction. Renormalizing the cointegrating relation on $b$ does not necessarily imply that $y_{t}$ determines $z_{t}$. In (22)-(23), for example, $y_{t}$ is generated conditional on $z_{t}$, and $z_{t}$ is a pure random walk. In a more fully dynamic DGP, such as (11)-(12), Granger causality may exist in both directions, with no single direction of causation exclusively present.

The analytics of inversion have immediate implications for policy analysis, as this section's motivating example of money demand highlights. Economic policy often centers on the determinants of inflation. Non-invertibility of a money-demand equation suggests modeling inflation directly, rather than attempting to do so indirectly through modeling money demand. In this issue of the JBES, de Brouwer and Ericsson (1998), Durevall (1998), Juselius (1998), and Metin (1998) all model inflation directly. Doing so still allows examining the role of money in determining prices, but that examination is separate from modeling money demand itself; see also Juselius (1992). Modeling both prices and money also follows directly from the initial joint density (3), which implies distinct equations for money and prices, whether formulated as a joint density or in a conditional/marginal factorization.

\section{$5 \quad$ Impulse Response Analysis}

Investigators often use impulse response analysis to ascertain responses by one set of variables to changes ("shocks") in another set of variables, where the latter set may include policy instruments. This section summarizes the analytics of impulse response analysis (Section 5.1), comments on its usefulness in policy analysis (Section 5.2), and examines the role of exogeneity in impulse response analysis (Section 5.3). See Sims (1980), Runkle (1987), and Lütkepohl (1991) inter alia for further details on the use of impulse response analysis in economics.

\subsection{A Summary}

Empirical impulse responses are typically calculated from a finite-lag VAR with possibly integrated variables and with various deterministic series such as a trend, seasonal dummies, and an intercept. The essential features of impulse response analysis can 
be ascertained from a simpler structure, such as (4) as a stationary first-order VAR $(s=1)$ with its only deterministic series being an intercept $\left(K q_{t}=\delta\right)$. The moving average (MA) representation of this stationary system is:

$$
\begin{aligned}
x_{t} & =\left(I_{N}-A L\right)^{-1}\left(\delta+\varepsilon_{t}\right) \\
& =\sum_{h=0}^{\infty} C_{h}\left(\delta+\varepsilon_{t-h}\right) \\
& =C(L)\left(\delta+\varepsilon_{t}\right),
\end{aligned}
$$

where $A=A_{1}$, the $C_{h}$ are $N \times N$ matrices of moving average coefficients, and $C(\cdot)$ is the corresponding matrix polynomial. Higher-order vector autoregressive systems can be accommodated through companion-form representation, at the expense of complicating the algebra without yielding further insights. Unit roots in cointegrated systems can be accommodated by mapping from $\mathrm{I}(1)$ to $\mathrm{I}(0)$ variables, as in (9). We consider only invertible MA representations: Hannan $(1960,1970)$ and Whittle (1963) inter alia discuss the relative merits of invertible and non-invertible MA processes.

The matrix of responses of $x_{t+h}$ to unit impulses in each of the elements of $\varepsilon_{t}$ equals $C_{h}$ :

$$
\frac{\partial x_{t+h}}{\partial \varepsilon_{t}^{\prime}}=C_{h}=(A)^{h} .
$$

Plotting a typical element $\partial x_{j, t+h} / \partial \varepsilon_{i t}$ against $h$ for $h=0,1,2, \ldots, H$ graphically presents the impulse response function of $x_{j}$ to $\varepsilon_{i}$. There are $N^{2}$ such graphs corresponding to $i, j=1,2, \ldots, N$. Although (25) is a convenient mathematical relation, the literature also often interprets $\varepsilon$ as economic shocks (rather than as just residuals), and so interprets the impulse responses $\partial x_{t+h} / \partial \varepsilon_{t}^{\prime}$ as the responses of $x$ to those economic shocks. An alternative interpretation is that the impulse responses measure the adjustment of $x_{t+h}$ to a policy action $a_{t}$, where $a_{\tau}=\iota$ for $\tau=t$ ( $\iota$ being a unit vector), $a_{\tau}=0$ for $\tau \neq t$, and $\delta+a_{t}$ replaces $\delta$ in (24). Such policy actions shift the system's intercept and are (by assumption) autonomous. Although $\partial x_{t+h} / \partial \varepsilon_{t}^{\prime}$ and $\partial x_{t+h} / \partial a_{t}^{\prime}$ represent impulse responses, responses also can be calculated for persistent changes, e.g., with $\varepsilon_{\tau} \neq 0$ or $a_{\tau} \neq 0$ for $\tau \geq t$.

Analytically, $\partial x_{t+h} / \partial \varepsilon_{t}^{\prime}$ equals $\partial x_{t+h} / \partial a_{t}^{\prime}$. Even so, these two responses differ not only in their interpretations but also in their caveats. The first response measures the adjustment of $x$ to changes in the errors $\varepsilon$ consistent with their distribution [namely, $\left.\operatorname{IN}_{N}(0, \Sigma)\right]$, in effect requiring that the empirical residuals closely match the actual underlying economic shocks. They need not. The second response measures the adjustment of $x$ to autonomous shifts $a$ in the system's intercept, thus assuming that the VAR's parameters are invariant to the class of interventions defined by $a$. Such interventions may not have occurred in sample and, even if they have, the VAR may not be invariant to them. Under each interpretation, violation of the underlying 
assumptions could seriously mislead policy analysis, with (e.g.) incorrect signs for impulse responses resulting. See Hendry and Mizon (1998) for further discussion.

The formulation in (25) assumes a unit impulse for each shock $\varepsilon_{i t}$. That ignores differences in variability and units of measurement across the corresponding variables; and, by perturbing each $\varepsilon_{i t}$ while holding constant all other $\varepsilon_{j t}(j \neq i)$, it ignores the (usual) nondiagonality of $\Sigma$, the covariance matrix for $\varepsilon_{t}$. The first issue is often addressed by using impulses equal to the residuals' standard deviations. Orthogonalization and (more generally) identification schemes aim to address the second issue; see Bernanke (1986), Blanchard and Quah (1989), and King, Plosser, Stock, and Watson (1991). These adjustments to (25) are all particular cases of impulse response analysis applied to the original VAR premultiplied by a nonsingular transformation matrix $P^{\prime}$ :

$$
x_{t}^{*}=A^{*} x_{t-1}^{*}+\varepsilon_{t}^{*} \quad \varepsilon_{t}^{*} \sim \operatorname{IN}_{N}(0, Q),
$$

where $\delta=0$ (for simplicity), $x_{t}^{*}=P^{\prime} x_{t}, A^{*}=P^{\prime} A\left(P^{\prime}\right)^{-1}, \varepsilon_{t}^{*}=P^{\prime} \varepsilon_{t}$, and $Q=P^{\prime} \Sigma P$. The transformed impulse response matrix is:

$$
\begin{aligned}
\frac{\partial x_{t+h}^{*}}{\partial \varepsilon_{t}^{* \prime}} & =\left(A^{*}\right)^{h} \\
& =P^{\prime}(A)^{h}\left(P^{\prime}\right)^{-1} \\
& =P^{\prime} \frac{\partial x_{t+h}}{\partial \varepsilon_{t}^{\prime}}\left(P^{\prime}\right)^{-1}
\end{aligned}
$$

which differs from the raw response matrix in (25) for $P^{\prime} \neq I_{N}$. Orthogonalized impulse response analysis sets $P$ such that $Q=I_{N}$. Structural VAR analysis sets $P$ to correspond to an identified structure, which may have non-orthogonal errors. Premultiplication of $(27)$ by $\left(P^{\prime}\right)^{-1}$ yields $\left(\partial x_{t+h} / \partial \varepsilon_{t}^{\prime}\right)\left(P^{\prime}\right)^{-1}\left[=\partial x_{t+h} / \partial \varepsilon_{t}^{* \prime}\right]$, which may be of more interest than either (25) or (27), as $\partial x_{t+h} / \partial \varepsilon_{t}^{* \prime}$ gives the response of the original variables $x$ to the transformed impulses $\varepsilon^{*}$.

\subsection{Comments}

Prior to discussing the role of exogeneity in the analysis of impulse response functions, several general comments are germane. They pertain to dynamics, model specification, model estimation, structure, and constancy.

First, the roots of the model's companion matrix determine the model's dynamic properties, so impulse response analysis is an alternative way of presenting this information. In this vein, de Brouwer and Ericsson (1998, Figures 3b and 3d, this issue) plot normalized lag distributions for their conditional model of inflation, in effect calculating impulse responses for a partial (conditional) system.

Second, impulse response functions describe the dynamics of a model, not the dynamics of the variables in the model. For example, suppose that the DGP is a multivariate random walk. The impulse response functions calculated from an estimated 
VAR will rarely reveal the pure persistence of the shocks because the estimated roots will not be exactly unity. Model mis-specification can induce additional discrepancies between the properties of the model and those of the variables.

Third, impulse responses provide no additional information for evaluating the model, beyond what is available from the coefficient estimates of the model. See, however, Faust (1998), who proposes assessing the robustness of impulse responses to alternate identification schemes.

Fourth, model specification, as well as the data properties themselves, affects impulse response functions. In particular, specifying whether a variable is weakly or strongly exogenous can directly affect impulse responses, independently of whether that variable is weakly or strongly exogenous.

Fifth, empirical impulse response functions are determined by a model's estimated parameters, regardless of the corresponding estimator's properties or the model specification. Making policy inferences from an empirical impulse response analysis thus places a premium on having a congruent model that encompasses rival alternatives and is invariant to extensions of the information set used. Relatedly, estimated impulse responses at long horizons may be inconsistent if obtained from an unrestricted VAR with cointegrated variables; see Phillips (1998). Ignoring cointegration by differencing all the variables also generates problems by confounding short-run and long-run properties, which are central to impulse response analysis.

Sixth, if a model is congruent, encompassing, and invariant, it may contain some structure. However, a model with structure does not imply that the corresponding residuals are structural, as they usually are not invariant to extensions of the information set unless (e.g.) the model coincides with the DGP. Increasing or reducing the dimension of $x$ directly affects $\varepsilon$, and $\varepsilon$ is also indirectly affected by conditioning on or by partialing out putative exogenous variables. See Hendry (1995b, p. 1632).

Seventh, economic data often appear to have structural breaks, so a complete (or closed) VAR is unlikely to be empirically constant. Impulse responses are inherently sensitive to parameter change, both from in-sample nonconstancy and because impulse response analysis assumes super exogeneity for the counterfactual shocks generating the responses. Impulse responses from a nonconstant (or non-invariant) VAR are clearly problematic to interpret for policy analysis. Notwithstanding that difficulty, empirical constancy of the estimated VAR is rarely checked in impulse response analysis. A conditional model, in contrast to a complete VAR, may achieve constancy, precisely by conditioning on those variables generating the (shared) breaks in the time series. That close relation between constancy, invariance, and super exogeneity motivates the remainder of this section, which examines how the assumed and actual exogeneity of variables affects impulse response analysis. 


\subsection{Exogeneity and Impulse Response Analysis}

Exogeneity has several specific implications for impulse response analysis. As in Section 2, consider the conditional/marginal factorization. For a first-order stationary VAR, that factorization generates:

$$
\left[\begin{array}{l}
y_{t} \\
z_{t}
\end{array}\right]=\left[\begin{array}{ccc}
D & \left(A_{11}-D A_{21}\right) & \left(A_{12}-D A_{22}\right) \\
0 & A_{21} & A_{22}
\end{array}\right]\left[\begin{array}{c}
z_{t} \\
y_{t-1} \\
z_{t-1}
\end{array}\right]+\left[\begin{array}{c}
v_{1 t} \\
\varepsilon_{2 t}
\end{array}\right]
$$

where $z_{t}$ need not enter the conditional distribution (e.g., policy may act only at a lag). Irrespective of the actual exogeneity status of $z_{t}$, the equation for $y_{t}$ in (28) implies that modeling the conditional distribution alone will result in the following impulse response matrices:

$$
\begin{aligned}
& \frac{\partial y_{t+h}}{\partial v_{1 t}^{\prime}}=\left(A_{11}-D A_{21}\right)^{h} \\
& \frac{\partial y_{t+h}}{\partial v_{1 t}^{\dagger \prime}}=\left(A_{11}-D A_{21}\right)^{h}\left(P^{\dagger \prime}\right)^{-1}
\end{aligned}
$$

where $v_{1 t}^{\dagger}=P^{\dagger \prime} v_{1 t}$, and $P^{\dagger}$ is an $m \times m$ matrix such that $P^{\dagger \prime} \Omega_{11} P^{\dagger}=I_{m}$.

The impulse responses for $y$ derived from the system equal those derived from the conditional model under the following (sufficient) conditions. From (25) and (29), the raw impulse responses are equal if $A_{21}=0$, i.e., $y$ does not Granger-cause $z$. In effect, strong exogeneity ensures that the parameters for multi-step ahead calculations are isolated in the conditional model. From (27) and (30), the orthogonalized impulse responses are equal if $A_{21}=0$ and if, in addition, $\Sigma_{12}=0$ (i.e., $y_{t}$ and $z_{t}$ are contemporaneously uncorrelated) and $P_{21}$ is set to zero (allowing $P_{11}=P^{\dagger}$ ). Although sufficient, but not necessary, these conditions do give a sense for the sorts of restrictions required for partial and complete systems to yield the same impulse responses. Conversely, weak exogeneity of $z_{t}$ for $\lambda_{1}$ is not sufficient to ensure equivalence of impulse responses from the conditional model and the system, whether they are raw or orthogonalized responses.

At a more general level, many identification schemes for a structural VAR (including orthogonal ones with triangular $P$ ) correspond to conditional/marginal factorizations. If regime shifts occur in the policy variables, then (essentially) at most one factorization isolates the invariants of the process, as follows from Hendry (1988) and the preceding discussion of super exogeneity. Tests for super exogeneity are thus a promising direction for identifying a VAR empirically, rather than relying on arbitrary (and untestable) identification assumptions. Put somewhat differently, even though factorization orthogonalizes, the corresponding transformed variables $z_{t}^{*}$ need not be weakly exogenous for the parameters of interest, and the latter might fail to be invariant to (possibly policy-induced) regime shifts in the marginal process for $z_{t}$. 


\section{A Small Empirical Policy Model for the United Kingdom}

This section illustrates the feasibility of and issues in conditional economic policy analysis. The analysis begins with a four-equation system of money, prices, output, and interest rates in the United Kingdom, from which Sections 6.1 and 6.2 develop two conditional subsystems and test for super exogeneity via parameter constancy tests. Section 6.3 compares impulse responses from the complete system and the two subsystems.

The data are nominal narrow money M1 $(M$, in $£$ millions), real total final expenditure (TFE) at 1985 prices $(I$, in $£$ millions), the TFE deflator $(P, 1985=1.00)$, and the (learning-adjusted) opportunity cost of holding M1 ( $R$, per cent per annum, expressed as a fraction). The data are quarterly and span 1963Q1-1989Q2. Allowing for lags, estimation uses the 100 observations 1964Q3-1989Q2. Money, TFE, and the deflator are seasonally adjusted, but $R$ is not. Lowercase letters denote logs of the corresponding uppercase variables. Hendry and Ericsson (1991) and Ericsson, Hendry, and Tran (1994) provide further details on the data.

Model formulation follows Hendry and Mizon (1993) and Hendry and Doornik (1994). The variables modeled are $m-p, i, \Delta p$, and $R$, with an intercept, a linear trend (restricted to the cointegration space), and two dummy variables, DOUT and DOIL. These dummies aim to capture output shocks from UK government policy and the two oil crises. The stochastic series appear to be $\mathrm{I}(1)$, although $R$ is probably $\mathrm{I}(0)$ after 1984, when it becomes a differential between competing interest rates. Hendry and Doornik (1994) model the joint behavior of the four stochastic variables, starting with an unrestricted fourth-order VAR and simplifying that VAR to an unrestricted second-order VAR and thence to an over-identified dynamic system, following the reduction approach of Hendry, Neale, and Srba (1988), as extended for cointegration by Hendry and Mizon (1993). Hendry and Doornik find two cointegration vectors, one for money demand and one for goods demand. The former enters only the money equation, whereas the latter enters the remaining three equations. Hendry and Doornik's final dynamic model appears to be congruent with the sample evidence, excepting some possible changes around the mid-1970s in the error variances for the inflation and interest-rate equations. Additional analyses of this dataset include Ericsson, Campos, and Tran (1990), Boswijk (1992), Johansen (1992e), Ericsson, Hendry, and Tran (1994), and Harbo, Johansen, Nielsen, and Rahbek (1998, this issue).

The current empirical analysis aims to implement the theoretical notions from the earlier sections, so two alternative conditional models are developed from the unrestricted four-variable second-order VAR, and impulse responses are constructed from those models and from the original VAR. In the first conditional subsystem, 
the interest rate is treated as weakly exogenous. The interest rate appears to be empirically weakly exogenous for the money-demand cointegrating vector but not for the goods-demand cointegrating vector. That said, feedback from goods demand onto the interest rate is small numerically and only barely significant statistically, so weak exogeneity of the interest rate for both cointegrating vectors appears to be approximately satisfied empirically. In the second conditional subsystem, money (rather than the interest rate) is treated as weakly exogenous, and a simplified model is again constructed. Small multiples of graphs summarize the subsystems' constancy properties and the impulse responses.

\subsection{A Money-demand Formulation}

This subsection tests for cointegration in the first conditional subsystem, calculates various diagnostic statistics for the resulting model, and demonstrates super exogeneity. The first panel in Table 1 reports cointegration test statistics for the threeequation, second-order VAR of $m-p, i$, and $\Delta p$, conditional on $R$. The dummies (DOUT and DOIL), $\Delta R_{t}$, and $\Delta R_{t-1}$ enter unrestrictedly, whereas the trend and $R_{t-1}$ are restricted to lie in the cointegration space. The results support two cointegrating vectors, similar to those found by earlier researchers. The second and third panels in Table 1 report unrestricted standardized estimates of those cointegrating vectors and their associated feedback coefficients. The first cointegrating vector is recognizably the money-demand relation in Hendry and Ericsson (1991) and Hendry and Doornik (1994), with a near unit income elasticity, large negative long-run semi-elasticities for inflation and the interest rate, and a negligible trend. The second cointegrating vector is similar to Hendry and Doornik's relation for aggregate goods demand, with the deviation of output from trend being positively related to inflation and negatively related to the interest rate. As shown by Harbo, Johansen, Nielsen, and Rahbek (1998, this issue), this cointegration analysis does not depend on nuisance parameters if weak exogeneity is valid.

The following restrictions were placed on the cointegrating vectors in Table 1. For money demand, income has a unit elasticity, $\Delta p$ and $R$ have equal effects (and equal to +7$)$, and the trend has a zero coefficient. The unrestricted coefficients on $\Delta p$ and $R$ are both numerically close to +7 , although imposing them as such has no direct economic interpretation, so this restriction serves mainly to obtain greater parsimony. For goods demand, the trend coefficient is imposed at 0.0063 (equal to the sample mean of $\Delta i$ ), real money has no effect, and $\Delta p$ and $R$ have coefficients of -4 and +1 , interpretable (prior to 1985) as an effect from the "real interest rate" $R-4 \Delta p$. These restricted cointegration vectors were then tested for lying in the cointegration space. The associated test statistic is asymptotically $\chi^{2}(\cdot)$ : the hypothesis is linear, cointegration rank is preserved, and the system is in $\mathrm{I}(0)$ space. The value of the statistic is $\chi^{2}(6)=1.86$, insignificant at the $5 \%$ level. The last 
Table 1. A Conditional Cointegration Analysis of UK Money Demand Data

\begin{tabular}{|c|c|c|c|c|c|}
\hline \multirow[b]{2}{*}{ Statistic type } & \multicolumn{5}{|c|}{ Variables in the cointegrating relations } \\
\hline & $m-p$ & $i$ & $\Delta p$ & $R$ & trend \\
\hline & \multicolumn{5}{|c|}{ Summary statistics and cointegration test statistics } \\
\hline Null hypothesis & $r=0$ & $r \leq 1$ & $r \leq 2$ & & \\
\hline Eigenvalue & 0.55 & 0.13 & 0.08 & & \\
\hline Maximal eigenvalue & $74.5^{* *}$ & 13.0 & 7.9 & & \\
\hline $95 \%$ critical value & 25.5 & 19.0 & 12.3 & & \\
\hline Trace eigenvalue & $95.3^{* *}$ & 20.8 & 7.9 & & \\
\hline \multirow[t]{2}{*}{$95 \%$ critical value } & 49.6 & 30.5 & 15.2 & & \\
\hline & \multicolumn{5}{|c|}{ Unrestricted standardized eigenvectors $\beta^{\prime}$} \\
\hline \multirow[t]{2}{*}{ Variable } & $\begin{array}{c}m-p \\
1 \\
-0.07\end{array}$ & $\begin{array}{c}i \\
-0.99 \\
1\end{array}$ & $\begin{array}{c}\Delta p \\
7.39 \\
-3.10\end{array}$ & $\begin{array}{c}R \\
7.64 \\
0.68\end{array}$ & $\begin{array}{c}\text { trend } \\
-0.000563 \\
-0.006019\end{array}$ \\
\hline & \multicolumn{5}{|c|}{ Unrestricted standardized adjustment coefficients $\alpha$} \\
\hline $\begin{array}{l}m-p \\
i \\
\Delta p\end{array}$ & $\begin{array}{l}-0.089 \\
-0.022 \\
-0.001\end{array}$ & $\begin{array}{r}-0.060 \\
-0.099 \\
0.102\end{array}$ & & & \\
\hline$\Delta p$ & \multicolumn{5}{|c|}{ Restricted standardized eigenvectors $\beta^{\prime}$} \\
\hline \multirow[t]{4}{*}{ Variable } & $m-p$ & $i$ & $\Delta p$ & $R$ & trend \\
\hline & 1 & -1 & 7 & 7 & 0 \\
\hline & 0 & 0.25 & -1 & 0.25 & -0.001575 \\
\hline & \multicolumn{5}{|c|}{ Restricted standardized adjustment coefficients $\alpha$} \\
\hline$m-p$ & $\begin{array}{c}-0.099 \\
(0.011)\end{array}$ & $\begin{array}{r}-0.229 \\
(0.206)\end{array}$ & & & \\
\hline$i$ & $\begin{array}{c}-0.024 \\
(0.008)\end{array}$ & $\begin{array}{r}-0.114 \\
(0.153)\end{array}$ & & & \\
\hline$\Delta p$ & $\begin{array}{r}-0.000 \\
(0.005)\end{array}$ & $\begin{array}{c}0.315 \\
(0.092)\end{array}$ & & & \\
\hline
\end{tabular}

NOTE: Johansen's maximal eigenvalue and trace eigenvalue statistics for testing cointegration are adjusted for degrees of freedom. The null hypothesis is in terms of the cointegration rank $r$ and, e.g., rejection of $r=0$ is evidence in favor of at least one cointegrating vector. Critical values for the trace statistic are taken from Harbo, Johansen, Nielsen, and Rahbek (1998, Table B.1, this issue). No critical values for the max statistic have been tabulated for conditional models, so the reported critical values are those from Osterwald-Lenum (1992, Table $2^{*}$ ) for a complete system. Asterisks ${ }^{*}$ and ${ }^{* *}$ denote significance at the $5 \%$ and $1 \%$ levels respectively, and estimated standard errors appear in parentheses $(\cdot)$. 
two panels in Table 1 report the corresponding restricted values of the cointegrating vectors, their associated feedback coefficients, and the standard errors for the latter. The constructed equilibrium-correction terms from $\beta^{\prime} x_{t}$ are:

$$
\begin{aligned}
& c_{1 t}=m_{t}-p_{t}-i_{t}+7 \Delta p_{t}+7 R_{t}-0.207 \\
& c_{2 t}=0.25\left(i_{t}-0.0063 t\right)-\Delta p_{t}+0.25 R_{t}-2.7516
\end{aligned}
$$

The dominant long-run feedback effects are of $c_{1}$ in the money equation and of $c_{2}$ in the inflation equation.

This system determines the five variables $\left(\Delta(m-p)_{t}, \Delta i_{t}, \Delta^{2} p_{t}, c_{1 t}, c_{2 t}\right)$, similar to (9). The formulation in the differences of the original variables, together with the equilibrium corrections, permits a more useful impulse response analysis in Section 6.3. The $\mathrm{I}(0)$ conditioning variables comprise $\Delta(m-p)_{t-1}, \Delta i_{t-1}, \Delta^{2} p_{t-1}, \Delta R_{t}, \Delta R_{t-1}$, $c_{1 t-1}, c_{2 t-1}, D O U T, D O I L$, and an intercept. The correlations between actual and fitted values for the stochastic variables are $0.85,0.69$, and 0.69 respectively. Diagnostic tests were calculated for fifth-order serial correlation, fourth-order autoregressive conditional heteroscedasticity, general heteroscedasticity, and nonnormality; see Godfrey (1978), Engle (1982), White (1980), and Doornik and Hansen (1994). The outcomes were satisfactory, other than some evidence of nonnormality and heteroscedasticity in the inflation equation.

Figure 1 plots recursive statistics for checking parameter constancy in this conditional subsystem. The statistics are one-step residuals with plus-or-minus twice the corresponding equation standard errors $\left(0 \pm 2 \hat{\sigma}_{t}\right)$ for each equation; the scaled recursive log-likelihood for the subsystem; and break-point Chow (1960) statistics for each equation and for the subsystem, with the Chow statistics scaled by their one-off $1 \%$ significance levels. When viewed as a set, the Chow statistics can only be taken as informal diagnostics. That said, they provide greater detail about empirical constancy than (e.g.) an unknown break-point test statistic, which intentionally aggregates over outcomes for many possible sample splits. In particular, the Chow statistics and the one-step residuals provide evidence on the possible nature and timing of nonconstancy (if any), evidence that could be useful in further model development. Conversely, if no Chow statistic in a given sequence rejects (as for the money equation), that lack of rejection points to marked empirical constancy in the corresponding equation. The recursive plots suggest reasonable constancy for this conditional monetary system, albeit with the minor caveats for the inflation equation noted previously.

Section 3 sketches two procedures for testing super exogeneity: both point to empirical super exogeneity in this conditional subsystem. The first procedure uses evidence about parameter constancy for the conditional and marginal models. Figure 1 supports the constancy of the conditional model. In their Figure 7, Hendry and Ericsson (1991) plot break-point Chow statistics for a marginal model of $R_{t}$, demonstrating considerable nonconstancy in that model. The second procedure is 

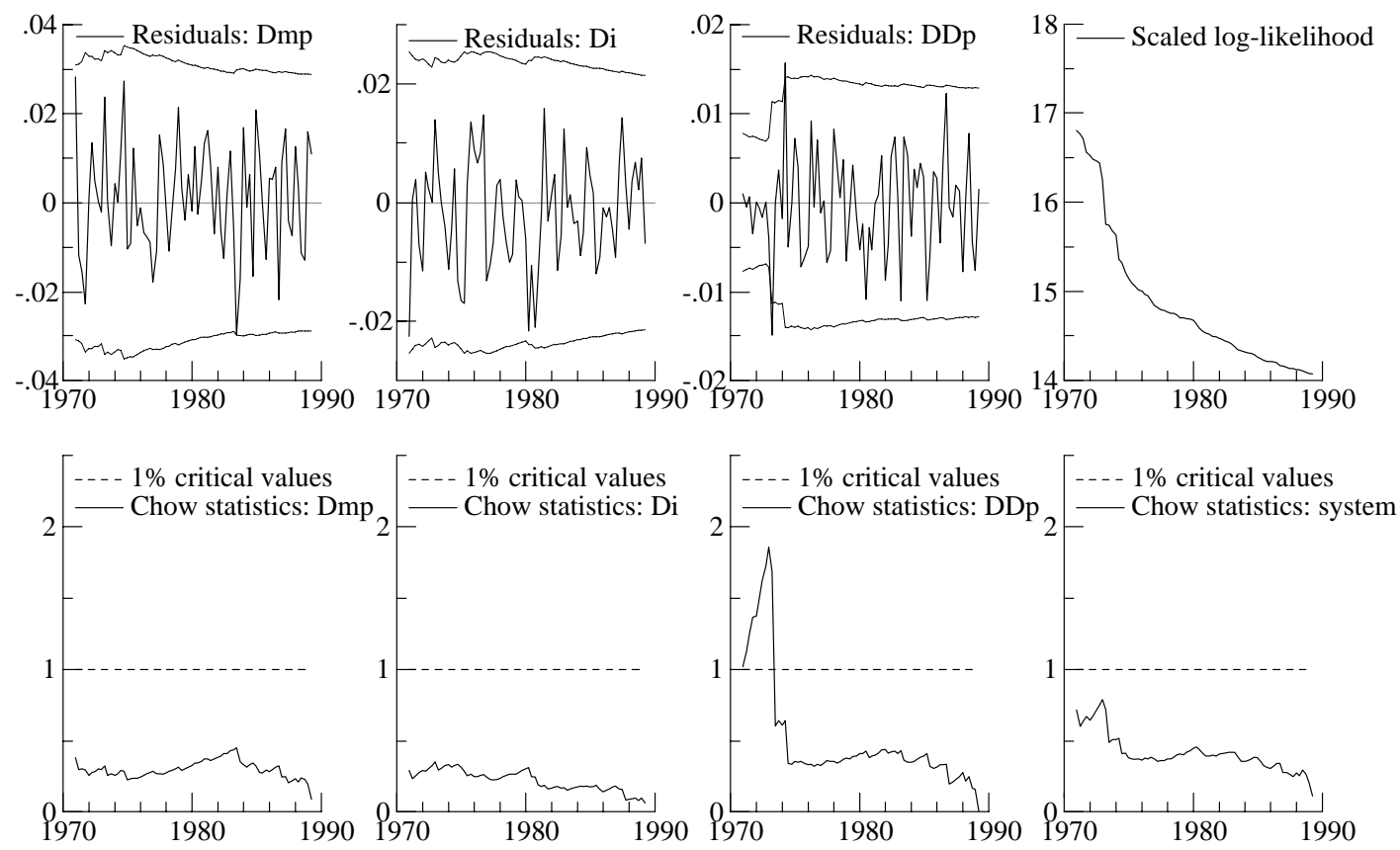

Figure 1: Recursive statistics for a conditional subsystem of money, income, and inflation: one-step residuals and $0 \pm 2 \hat{\sigma}_{t}$ for equations explaining $\Delta(m-p)_{t}, \Delta i_{t}$, and $\Delta^{2} p_{t}$; the scaled log-likelihood; and break-point Chow statistics for equations explaining $\Delta(m-p)_{t}, \Delta i_{t}$, and $\Delta^{2} p_{t}$, and for the conditional subsystem, with the statistics rescaled by their one-off $1 \%$ critical values. 

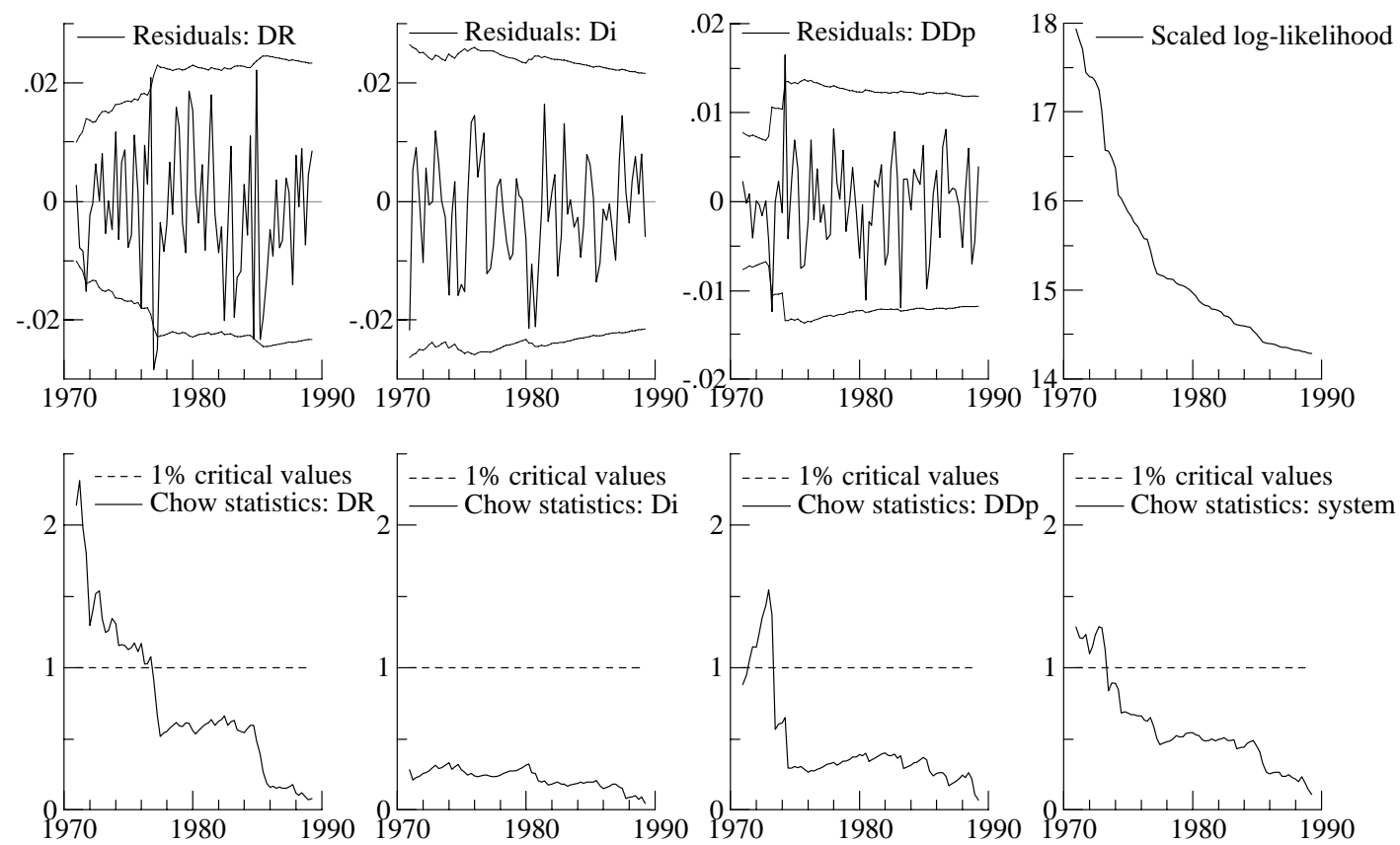

Figure 2: Recursive statistics for a conditional subsystem of the interest rate, income, and inflation: one-step residuals and $0 \pm 2 \hat{\sigma}_{t}$ for equations explaining $\Delta R_{t}, \Delta i_{t}$, and $\Delta^{2} p_{t}$; the scaled log-likelihood; and break-point Chow statistics for equations explaining $\Delta R_{t}, \Delta i_{t}$, and $\Delta^{2} p_{t}$, and for the conditional subsystem, with the statistics rescaled by their one-off $1 \%$ critical values. 
the variable-addition test of Engle and Hendry (1993). To check the super exogeneity of $\left(i_{t}, \Delta p_{t}, R_{t}\right)$ for the parameters of their money-demand equation, Hendry and Doornik (1994) test the significance of four dummy variables from Engle and Hendry (1993) and do not reject at the 5\% level. Both findings on super exogeneity are consistent with the money stock being endogenously determined by the private sector. Even with super exogeneity, the determinants of money demand could and did induce large shifts in the real money stock, which increased by nearly $100 \%$ during the last decade of the sample.

\subsection{An Interest-rate Formulation}

A similar analysis was undertaken for a reverse conditioning, in which $R_{t}, i_{t}$, and $\Delta p_{t}$ are treated as endogenous and $(m-p)_{t}$ as weakly exogenous. The cointegration space now includes $(m-p)_{t-1}$, and $\Delta(m-p)_{t}$ and $\Delta(m-p)_{t-1}$ enter the VAR unrestrictedly. This conditional analysis delivers one significant cointegrating relation and one nearly significant cointegrating relation, which are similar to those shown in Table 1. The first is recognizably the money-demand vector, but it enters all three equations, judging from the size and significance of the feedback coefficients. The second cointegrating vector appears to enter the equation for inflation. The cointegrating restrictions in (31)-(32) remain statistically acceptable.

Figure 2 reports the recursive sequences for this restricted, I(0), conditional VAR. Rejection occurs in the equations for both $R$ and $\Delta p$ during the early 1970s, and the system break-point statistic values are significant then as well. This reverse conditioning deleteriously affects parameter constancy in the model. Such results are consistent with earlier econometric analysis and with the institutional structure of the UK money market, in which the monetary authority determines the interest rate and the private sector their desired money balances, given that interest rate. Indeed, because analysis of the four-variable system finds $i_{t}, \Delta p_{t}$, and $R_{t}$ to be longrun weakly exogenous for the money-demand relation in the equation for $(m-p)_{t}$, conditioning on $(m-p)_{t}$ may account for the second conditional subsystem's relatively poor performance.

\subsection{Impulse Response Analysis}

This subsection derives impulse responses for the four-variable (complete) VAR and for each of the two conditional subsystems, in each case calculating the impulse responses of $\Delta(m-p)_{t}, \Delta i_{t}, \Delta^{2} p_{t}, c_{1 t}$, and $c_{2 t}$ to orthogonalized standard-deviation shocks in the income and inflation equations. Figure 3 plots the impulse responses for all three models in a panel representing selections from the derivative matrix $\partial x_{t+h} / \partial \varepsilon_{t}^{* \prime}$.

For calculating impulse responses, the first conditional model treats $R_{t}$ as strongly 
Response by:

Shock to Di

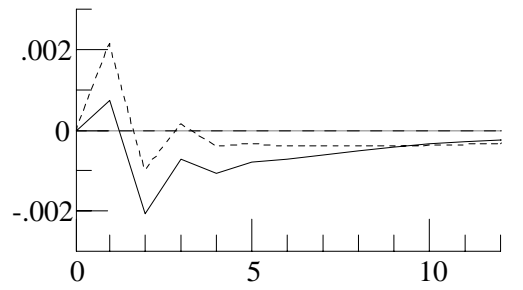

Di

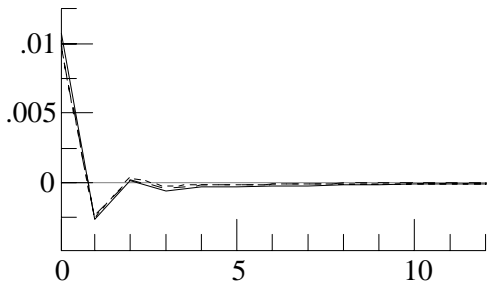

DDp

c1
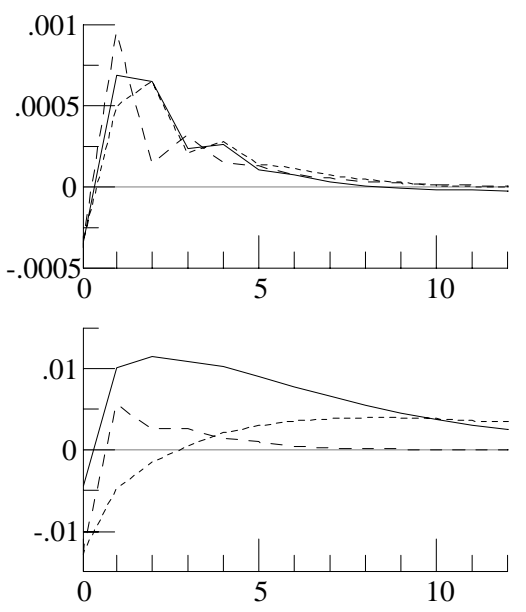

c2

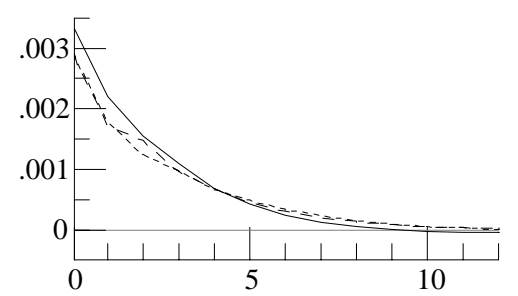

Shock to DDp
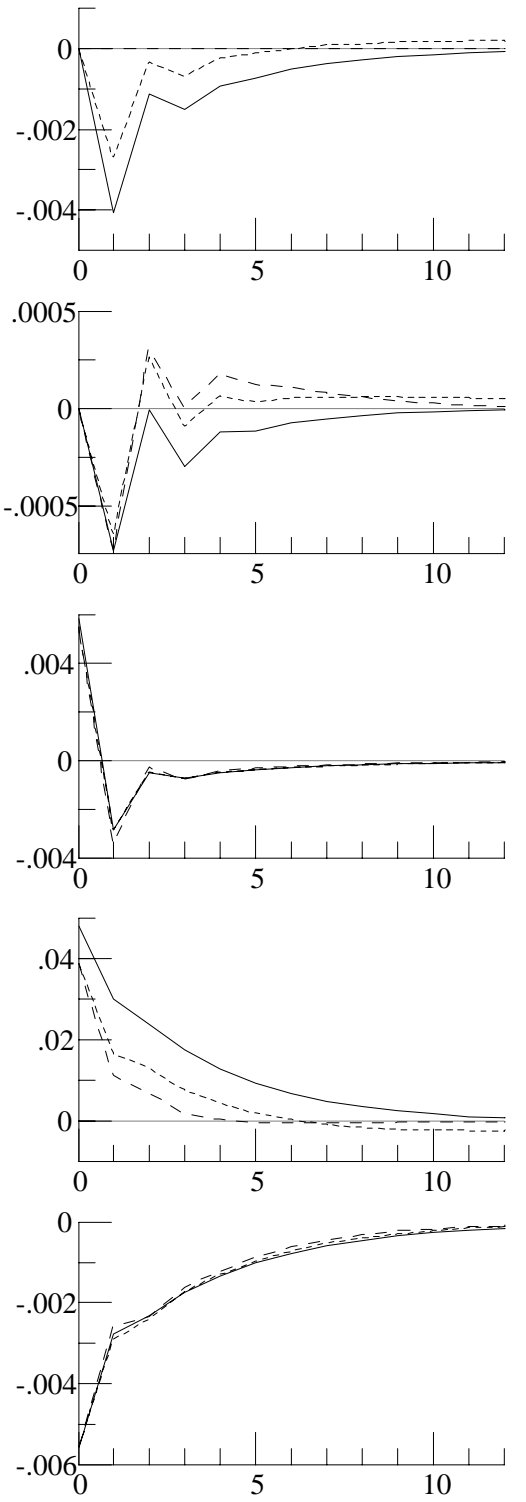

Figure 3: Impulse responses by $\Delta(m-p), \Delta i, \Delta^{2} p, c_{1}$, and $c_{2}$ to standard-deviation orthogonal income and inflation shocks in the complete system $(-)$, the subsystem conditional on $R_{t}(---)$, and the subsystem conditional on $(m-p)_{t}(--)$. 
exogenous. That model's orthogonal impulse responses differ substantially from those from the unconditional model because the residuals in the interest-rate equation are highly correlated with those of the money and inflation equations. The condition $\Sigma_{12}=0$ is not satisfied, even though Granger non-causality (corresponding to the condition $A_{21}=0$ in Section 5.3) holds empirically. The impulse responses from the second conditional model differ substantially from those of the other two models in numerous instances. Relatedly, $i, \Delta p$, and $R$ empirically Granger-cause $m-p$, contrary to the assumption of Granger non-causality embedded in the impulse responses for the second conditional model.

Many orthogonalizations violate weak exogeneity, and different exogeneity specifications directly affect impulse responses. Thus, it seems preferable to develop a valid conditional representation and avoid the use of orthogonalized impulse response analysis.

\subsection{Summary}

This section developed two conditional cointegrated subsystems from different factorizations of the data's joint distribution, and then drew inferences about constancy, invariance, super exogeneity, the Lucas critique, model inversion, and impulse response analysis for those two models. Tests of parameter constancy provided information about super exogeneity, which holds in the first subsystem, but not in the second. The second subsystem is a (partial) inversion of the first; and, as Section 4 implies, only one factorization typically obtains a constant conditional model. The empirical super exogeneity of the first conditional model refutes the Lucas critique in practice and argues against inversion. Even with super (and strong) exogeneity in the first subsystem, orthogonal impulse response analysis is still problematic because of certain nonzero contemporaneous residual covariances. These results elucidate how the concepts of exogeneity and cointegration can help interpret and guide econometric model use in economic policy analysis.

At a more general level, econometric models are subject to stringent requirements if their use in economic policy analysis is to deliver reliable inferences. Sufficient conditions are unrealistically demanding, so this paper has delineated several operational necessary conditions and considered how these conditions impinge on policy analysis. In particular, various forms of exogeneity and causality were highlighted, and were related to the key issue of parameter invariance.

Many potential approaches to policy analysis typically fail some of the necessary conditions and hence may not be viable. Inversion of an equation to derive instrument values for achieving a given target value may violate weak exogeneity. Moreover, statistical inference in conditional models may be hazardous unless the conditioning variables are weakly exogenous, even though Granger non-causality is sufficient for the equivalence of standard-error-based impulse responses from systems and condi- 
tional models. Although such impulse response analysis is invariant to the ordering of variables, it ignores the correlation between equation residuals. Orthogonalizing the residuals addresses this problem, but orthogonalization is not recommended nonetheless. In general, it violates weak exogeneity, and it can induce a sequential conditioning of variables that depends upon the initial order of the variables. That, in turn, may lose invariance of coefficients.

If economic policy analysis based on econometric models is to yield useful inferences, those models should be congruent with available information, embody valid weak exogeneity, and be invariant to policy changes. Tools such as inversion and impulse response analysis require careful handling if their implications are to match later realized outcomes.

\section{This Issue's Special Section on Exogeneity, Coin- tegration, and Economic Policy Analysis}

This first paper in this JBES special section provides a framework for discussing econometric models in economic policy analysis, focusing on the implications of and interrelations between cointegration and exogeneity. The second paper (by Harbo, Johansen, Nielsen, and Rahbek) develops the basis for inference about cointegration in conditional models, which arise naturally in a policy context. The remaining four papers (by Juselius, Metin, Durevall, and de Brouwer and Ericsson) are primarily empirical, developing (for the most part) conditional models of inflation. Inflation has been a longstanding concern of policymakers, as highlighted by the recent increased interest in inflation targeting. These four papers are not only substantive applied contributions in themselves for the countries considered (Denmark, Turkey, Brazil, and Australia). They also provide templates for similar analyses for other countries. The remainder of this section summarizes these articles.

Harbo, Johansen, Nielsen, and Rahbek analyze the likelihood ratio statistic for testing cointegration in conditional (or partial) models when weak exogeneity holds. Johansen's $(1988,1991)$ likelihood ratio statistic for testing cointegration in complete vector autoregressive models has been popular in practice. Weak exogeneity often appears to be satisfied empirically, so cointegration tests that assume weak exogeneity have a strong appeal. The authors derive the statistic's asymptotic distribution, show its invariance to nuisance parameters, and tabulate critical values; and they discuss the roles of the various assumptions underlying the procedure, focusing on

the implications of deterministic variables. To illustrate the approach, the authors test for cointegration in two conditional models involving real money (M1), inflation, income, and a net interest rate for the United Kingdom.

Juselius develops a multiple-equation model for money, prices, income, and interest rates for Denmark. Money and prices appear to be $\mathrm{I}(2)$; and they cointegrate 
to form real money, which is $\mathrm{I}(1)$. The presence of $\mathrm{I}(2)$ variables complicates the econometric implementation and the corresponding economic interpretation. Nominal money and prices appear to be I(2) for many other countries as well, however, so Juselius's approach may serve as a blueprint for modeling such I(2) variables. Juselius sequentially considers long-run I(2) properties, long-run I(1) properties, and shortrun structure in the process of constructing a model for real money, inflation, and the domestic deposit interest rate, conditional on income and the domestic bond rate. The empirical weak exogeneity of income and the domestic bond rate help simplify both the cointegration analysis and the modeling of short-run effects; and tests of the conditional model's constancy help demonstrate the super exogeneity of those variables. A policy regime shift in 1983 proves central to the design and evaluation of the conditional model. A marginal model for the domestic bond rate, conditional on the German bond rate, elucidates an important international aspect to the Danish economy, an aspect that may be similar for many other small open economies.

Metin models the relationship between inflation and the public sector deficit in Turkey. A vector autoregressive analysis finds three stationary relations involving output growth, inflation, the deficit, the monetary base, and a trend. Output growth itself is stationary, and so constitutes a trivial cointegrating (stationary) combination. The second cointegrating vector involves inflation, the deficit, and the monetary base; and the third involves inflation, the deficit, and a trend. Weak exogeneity does not hold, so single-equation conditional modeling of inflation proceeds by taking the system estimates of the cointegrating vectors as given, following the approach of Juselius (1992). Even though major regime shifts occurred in sample, with inflation ranging from $0 \%$ to $100 \%$ per annum, the resulting equilibrium-correction model is empirically constant, thus demonstrating super exogeneity of the remaining (shortrun) parameters of the conditional model. Economically, budget deficits, real income growth, and debt monetization all affect Turkish inflation.

Durevall evaluates contending theories for the determination of Brazilian inflation by allowing feedback effects from disequilibria in relationships based on purchasing power parity and money demand. Because of the number of variables and the shortness of the sample, the two corresponding cointegrating relationships are obtained from separate analyses, paralleling Juselius (1992). Inflation appears to be I(1), so the econometric methodology is closely related to that of Juselius (1998, this issue). From the conditional model derived for inflation, its primary long-run determinant appears to be deviations from a generalized version of purchasing power parity. Although the growth rate of nominal money directly affects inflation, its level (through disequilibria in money demand) does not. Additional encompassing tests also rule out the direct influence of wages and the output gap on inflation. That said, indirect effects of such variables are possible through the determination of the exchange rate and the domestic interest rate.

Finally, de Brouwer and Ericsson develop an empirically constant equilibrium- 
correction model for Australian inflation, in which the level of consumer prices adjusts dynamically to relative aggregate demand and to a markup of prices over domestic and import costs. Domestic and import costs are weakly exogenous, thereby sustaining conditional modeling. The resulting model encompasses a range of economic models for prices and inflation, including a variant of the price-inflation Phillips curve, wageprice models, and purchasing power parity. Each of these economic theories, however, provides only a partial explanation of empirical price behavior in Australia: several economic determinants are necessary to understand the behavior of the Australian consumer price index in practice.

\section{Appendix. Table of Contents for the Special Sec- tion on Exogeneity, Cointegration, and Economic Policy Analysis}

1. "Associate Editor's Introduction"

Neil R. Ericsson

2. "Exogeneity, Cointegration, and Economic Policy Analysis"

Neil R. Ericsson, David F. Hendry, and Grayham E. Mizon

3. "Asymptotic Inference on Cointegrating Rank in Partial Systems" Ingrid Harbo, Søren Johansen, Bent Nielsen, and Anders Rahbek

4. "A Structured VAR for Denmark Under Changing Monetary Regimes" Katarina Juselius

5. "The Relationship Between Inflation and the Budget Deficit in Turkey" Kıvılcım Metin

6. "The Dynamics of Chronic Inflation in Brazil, 1968-1985"

Dick Durevall

7. "Modeling Inflation in Australia"

Gordon de Brouwer and Neil R. Ericsson 


\section{References}

Banerjee, A., J. J. Dolado, J. W. Galbraith, and D. F. Hendry (1993) Co-integration, Error Correction, and the Econometric Analysis of Non-stationary Data, Oxford University Press, Oxford.

Banerjee, A., D. F. Hendry, and G. E. Mizon (1996) "The Econometric Analysis of Economic Policy", Oxford Bulletin of Economics and Statistics, 58, 4, 573-600.

Barndorff-Nielsen, O. E. (1978) Information and Exponential Families: In Statistical Theory, John Wiley, Chichester.

Barro, R. J. (1997) Macroeconomics, MIT Press, Cambridge, Massachusetts, Fifth Edition.

Bernanke, B. S. (1986) "Alternative Explanations of the Money-Income Correlation", in K. Brunner and A. H. Meltzer (eds.) Real Business Cycles, Real Exchange Rates and Actual Policies, North-Holland, Amsterdam, Carnegie-Rochester Conference Series on Public Policy, Volume 25, 49-99 (with discussion).

Blanchard, O. J., and D. Quah (1989) "The Dynamic Effects of Aggregate Demand and Supply Disturbances", American Economic Review, 79, 4, 655-673.

Bontemps, C., and G. E. Mizon (1997) "Congruence and Encompassing", mimeo, Economics Department, European University Institute, Florence, Italy, June.

Boswijk, H. P. (1992) Cointegration, Identification and Exogeneity: Inference in Structural Error Correction Models, Thesis Publishers, Amsterdam (Tinbergen Institute Research Series, Volume 37).

Boswijk, H. P. (1994) "S-Ancillarity and Strong Exogeneity", mimeo, Department of Actuarial Science and Econometrics, University of Amsterdam, Amsterdam, The Netherlands, September.

Boswijk, H. P. (1995) "Efficient Inference on Cointegration Parameters in Structural Error Correction Models", Journal of Econometrics, 69, 1, 133-158.

de Brouwer, G., and N. R. Ericsson (1998) "Modelling Inflation in Australia", Journal of Business and Economic Statistics, 16, 4, forthcoming.

Bryant, R. C., D. W. Henderson, G. Holtham, P. Hooper, and S. A. Symansky (eds.) (1988) Empirical Macroeconomics for Interdependent Economies, The Brookings Institution, Washington, D.C.

Bryant, R. C., P. Hooper, and C. L. Mann (eds.) (1993) Evaluating Policy Regimes: New Research in Empirical Macroeconomics, The Brookings Institution, Washington, D.C.

Chow, G. C. (1960) "Tests of Equality Between Sets of Coefficients in Two Linear Regressions", Econometrica, 28, 3, 591-605.

Davidson, J. E. H., and S. Hall (1991) "Cointegration in Recursive Systems", Economic Journal, 101, 405, 239-251.

Dolado, J. J. (1992) "A Note on Weak Exogeneity in VAR Cointegrated Models", Economics Letters, 38, 2, 139-143.

Doornik, J. A., and H. Hansen (1994) "An Omnibus Test for Univariate and Multivariate Normality", Discussion Paper No. W4\&91, Nuffield College, Oxford, England, November. 
Doornik, J. A., and D. F. Hendry (1996) PcGive Professional 9.0 for Windows, International Thomson Business Press, London.

Durevall, D. (1998) "The Dynamics of Chronic Inflation in Brazil, 1968-1985", Journal of Business and Economic Statistics, 16, 4, forthcoming.

Edison, H. J., J. R. Marquez, and R. W. Tryon (1987) "The Structure and Properties of the Federal Reserve Board Multicountry Model", Economic Modelling, 4, 2, 115-315.

Engle, R. F. (1982) "Autoregressive Conditional Heteroscedasticity with Estimates of the Variance of United Kingdom Inflation", Econometrica, 50, 4, 987-1007.

Engle, R. F., and C. W. J. Granger (1987) "Co-integration and Error Correction: Representation, Estimation, and Testing", Econometrica, 55, 2, 251-276.

Engle, R. F., and D. F. Hendry (1993) "Testing Super Exogeneity and Invariance in Regression Models", Journal of Econometrics, 56, 1/2, 119-139.

Engle, R. F., and D. F. Hendry (1994) "Testing Super Exogeneity and Invariance in Regression Models", Chapter 4 in N. R. Ericsson and J. S. Irons (eds.) Testing Exogeneity, Oxford University Press, Oxford, 93-119.

Engle, R. F., D. F. Hendry, and J.-F. Richard (1983) "Exogeneity", Econometrica, 51, 2, 277-304.

Ericsson, N. R. (1992) "Cointegration, Exogeneity, and Policy Analysis: An Overview", Journal of Policy Modeling, 14, 3, 251-280.

Ericsson, N. R. (1995) "Conditional and Structural Error Correction Models", Journal of Econometrics, 69, 1, 159-171.

Ericsson, N. R., J. Campos, and H.-A. Tran (1990) "PC-GIVE and David Hendry's Econometric Methodology", Revista de Econometria, 10, 1, 7-117.

Ericsson, N. R., D. F. Hendry, and H.-A. Tran (1994) "Cointegration, Seasonality, Encompassing, and the Demand for Money in the United Kingdom", Chapter 7 in C. P. Hargreaves (ed.) Nonstationary Time Series Analysis and Cointegration, Oxford University Press, Oxford, 179-224.

Ericsson, N. R., and J. S. Irons (eds.) (1994) Testing Exogeneity, Oxford University Press, Oxford.

Ericsson, N. R., and J. S. Irons (1995) "The Lucas Critique in Practice: Theory Without Measurement", Chapter 8 in K. D. Hoover (ed.) Macroeconometrics: Developments, Tensions and Prospects, Kluwer Academic Publishers, Boston, Massachusetts, 263-312 (with discussion).

Fair, R. C. (1984) Specification, Estimation, and Analysis of Macroeconometric Models, Harvard University Press, Cambridge, Massachusetts.

Faust, J. (1998) "The Robustness of Identified VAR Conclusions about Money", International Finance Discussion Paper No. 610, Board of Governors of the Federal Reserve System, Washington, D.C., April.

Favero, C., and D. F. Hendry (1992) "Testing the Lucas Critique: A Review", Econometric Reviews, 11, 3, 265-306 (with discussion).

Florens, J.-P., and M. Mouchart (1985) "Conditioning in Dynamic Models", Journal of Time Series Analysis, 6, 1, 15-34. 
Friedman, M., and A. J. Schwartz (1982) Monetary Trends in the United States and the United Kingdom: Their Relation to Income, Prices, and Interest Rates, 1867-1975, University of Chicago Press, Chicago.

Frisch, R. (1938) "Statistical versus Theoretical Relations in Economic Macrodynamics", mimeo, League of Nations, 17 July 1938 (Reprinted as "Autonomy of Economic Relations", Chapter 37 in D. F. Hendry and M. S. Morgan (eds.) (1995) The Foundations of Econometric Analysis, Cambridge University Press, Cambridge).

Godfrey, L. G. (1978) "Testing Against General Autoregressive and Moving Average Error Models When the Regressors Include Lagged Dependent Variables", Econometrica, 46, 6, 1293-1301.

Gordon, R. J. (1976) "Can Econometric Policy Evaluations Be Salvaged? - A Comment", in K. Brunner and A. H. Meltzer (eds.) The Phillips Curve and Labor Markets, NorthHolland, Amsterdam, Carnegie-Rochester Conference Series on Public Policy, Volume 1, Journal of Monetary Economics, Supplement, 47-61.

Granger, C. W. J. (1969) "Investigating Causal Relations by Econometric Models and Cross-spectral Methods", Econometrica, 37, 3, 424-438.

Granger, C. W. J., and M. Deutsch (1992) "Comments on the Evaluation of Policy Models", Journal of Policy Modeling, 14, 4, 497-516.

Haavelmo, T. (1944) "The Probability Approach in Econometrics", Econometrica, 12, Supplement, i-viii, 1-118.

Hallman, J. J., R. D. Porter, and D. H. Small (1991) "Is the Price Level Tied to the M2 Monetary Aggregate in the Long Run?", American Economic Review, 81, 4, 841-858.

Hannan, E. J. (1960) Time Series Analysis, Methuen, London.

Hannan, E. J. (1970) Multiple Time Series, John Wiley, New York.

Harbo, I., S. Johansen, B. Nielsen, and A. Rahbek (1998) "Asymptotic Inference on Cointegrating Rank in Partial Systems", Journal of Business and Economic Statistics, 16, 4 , forthcoming.

Hendry, D. F. (1985) "Monetary Economic Myth and Econometric Reality", Oxford Review of Economic Policy, 1, 1, 72-84.

Hendry, D. F. (1988) "The Encompassing Implications of Feedback versus Feedforward Mechanisms in Econometrics", Oxford Economic Papers, 40, 1, 132-149.

Hendry, D. F. (1995a) Dynamic Econometrics, Oxford University Press, Oxford.

Hendry, D. F. (1995b) "Econometrics and Business Cycle Empirics", Economic Journal, 105, 433, 1622-1636.

Hendry, D. F. (1995c) "On the Interactions of Unit Roots and Exogeneity", Econometric Reviews, 14, 4, 383-419.

Hendry, D. F., and J. A. Doornik (1994) "Modelling Linear Dynamic Econometric Systems", Scottish Journal of Political Economy, 41, 1, 1-33.

Hendry, D. F., and N. R. Ericsson (1991) "Modeling the Demand for Narrow Money in the United Kingdom and the United States", European Economic Review, 35, 4, 833-881 (with discussion). 
Hendry, D. F., and G. E. Mizon (1992) "The Role of Weak Exogeneity in Econometric Model Policy Analyses", mimeo, Institute of Economics and Statistics, Oxford University, Oxford, England.

Hendry, D. F., and G. E. Mizon (1993) "Evaluating Dynamic Econometric Models by Encompassing the VAR", Chapter 18 in P. C. B. Phillips (ed.) Models, Methods, and Applications of Econometrics: Essays in Honor of A. R. Bergstrom, Blackwell Publishers, Cambridge, Massachusetts, 272-300.

Hendry, D. F., and G. E. Mizon (1998) "Exogeneity, Causality, and Co-breaking in Economic Policy Analysis of a Small Econometric Model of Money in the UK", Empirical Economics, forthcoming.

Hendry, D. F., A. J. Neale, and F. Srba (1988) "Econometric Analysis of Small Linear Systems using PC-FIML", Journal of Econometrics, 38, 1/2, 203-226.

Hoover, K. D., and S. M. Sheffrin (1992) "Causation, Spending, and Taxes: Sand in the Sandbox or Tax Collector for the Welfare State?", American Economic Review, 82, 1, $225-248$.

Johansen, S. (1988) "Statistical Analysis of Cointegration Vectors", Journal of Economic Dynamics and Control, 12, 2/3, 231-254.

Johansen, S. (1991) "Estimation and Hypothesis Testing of Cointegration Vectors in Gaussian Vector Autoregressive Models", Econometrica, 59, 6, 1551-1580.

Johansen, S. (1992a) "Cointegration in Partial Systems and the Efficiency of Single-equation Analysis", Journal of Econometrics, 52, 3, 389-402.

Johansen, S. (1992b) "Determination of Cointegration Rank in the Presence of a Linear Trend", Oxford Bulletin of Economics and Statistics, 54, 3, 383-397.

Johansen, S. (1992c) "An I(2) Cointegration Analysis of the Purchasing Power Parity Between Australia and the United States", Chapter 9 in C. P. Hargreaves (ed.) Macroeconomic Modelling in the Long Run, Edward Elgar, Aldershot, Hants., England, 229-248.

Johansen, S. (1992d) "A Representation of Vector Autoregressive Processes Integrated of Order 2", Econometric Theory, 8, 2, 188-202.

Johansen, S. (1992e) "Testing Weak Exogeneity and the Order of Cointegration in UK Money Demand Data", Journal of Policy Modeling, 14, 3, 313-334.

Johansen, S. (1995) Likelihood-based Inference in Cointegrated Vector Autoregressive Models, Oxford University Press, Oxford.

Johansen, S., and K. Juselius (1990) "Maximum Likelihood Estimation and Inference on Cointegration - With Applications to the Demand for Money", Oxford Bulletin of Economics and Statistics, 52, 2, 169-210.

Juselius, K. (1992) "Domestic and Foreign Effects on Prices in an Open Economy: The Case of Denmark", Journal of Policy Modeling, 14, 4, 401-428.

Juselius, K. (1998) "A Structured VAR for Denmark Under Changing Monetary Regimes", Journal of Business and Economic Statistics, 16, 4, forthcoming.

King, R. G., C. I. Plosser, J. H. Stock, and M. W. Watson (1991) "Stochastic Trends and Economic Fluctuations", American Economic Review, 81, 4, 819-840. 
Koopmans, T. C. (1950) "When Is an Equation System Complete for Statistical Purposes?", Chapter 17 in T. C. Koopmans (ed.) Statistical Inference in Dynamic Economic Models (Cowles Commission Monograph No. 10), John Wiley, New York, 393-409.

Lucas, Jr., R. E. (1976) "Econometric Policy Evaluation: A Critique", in K. Brunner and A. H. Meltzer (eds.) The Phillips Curve and Labor Markets, North-Holland, Amsterdam, Carnegie-Rochester Conference Series on Public Policy, Volume 1, Journal of Monetary Economics, Supplement, 19-46 (with discussion).

Lütkepohl, H. (1991) Introduction to Multiple Time Series Analysis, Springer-Verlag, Berlin.

Marschak, J. (1953) "Economic Measurements for Policy and Prediction", Chapter 1 in W. C. Hood and T. C. Koopmans (eds.) Studies in Econometric Method (Cowles Commission Monograph No. 14), John Wiley, New York, 1-26.

Metin, K. (1998) "The Relationship Between Inflation and the Budget Deficit in Turkey", Journal of Business and Economic Statistics, 16, 4, forthcoming.

Mizon, G. E. (1995) "Progressive Modeling of Macroeconomic Time Series: The LSE Methodology", Chapter 4 in K. D. Hoover (ed.) Macroeconometrics: Developments, Tensions, and Prospects, Kluwer Academic Publishers, Boston, Massachusetts, 107-170 (with discussion).

Mosconi, R., and C. Giannini (1992) "Non-causality in Cointegrated Systems: Representation, Estimation and Testing", Oxford Bulletin of Economics and Statistics, 54, 3, $399-417$.

Osterwald-Lenum, M. (1992) "A Note with Quantiles of the Asymptotic Distribution of the Maximum Likelihood Cointegration Rank Test Statistics", Oxford Bulletin of Economics and Statistics, 54, 3, 461-472.

Phillips, P. C. B. (1998) "Impulse Response and Forecast Error Variance Asymptotics in Nonstationary VARs", Journal of Econometrics, 83, 1/2, 21-56.

Phillips, P. C. B., and M. Loretan (1991) "Estimating Long-run Economic Equilibria", Review of Economic Studies, 58, 3, 407-436.

Richard, J.-F. (1980) "Models with Several Regimes and Changes in Exogeneity", Review of Economic Studies, 47, 1, 1-20.

Runkle, D. E. (1987) "Vector Autoregressions and Reality", Journal of Business and Economic Statistics, 5, 4, 437-442 (with discussion).

Sims, C. A. (1980) "Macroeconomics and Reality", Econometrica, 48, 1, 1-48.

Toda, H. Y., and P. C. B. Phillips (1993) "Vector Autoregressions and Causality", Econometrica, 61, 6, 1367-1393.

Toda, H. Y., and P. C. B. Phillips (1994) "Vector Autoregression and Causality: A Theoretical Overview and Simulation Study", Econometric Reviews, 13, 2, 259-285.

Urbain, J.-P. (1992) "On Weak Exogeneity in Error Correction Models", Oxford Bulletin of Economics and Statistics, 54, 2, 187-207.

White, H. (1980) "A Heteroskedasticity-consistent Covariance Matrix Estimator and a Direct Test for Heteroskedasticity", Econometrica, 48, 4, 817-838.

Whittle, P. (1963) Prediction and Regulation: By Linear Least-square Methods, D. Van Nostrand, Princeton, New Jersey. 